\title{
CFD Simulations for Arc-Jet Panel Testing Capability Development Using Semi-Elliptical Nozzles
}

\author{
Tahir Gökçen, ${ }^{*}$ John A. Balboni, ${ }^{\dagger}$ and G. Joseph Hartman ${ }^{*}$ \\ NASA Ames Research Center, Moffett Field, CA 94035
}

\begin{abstract}
This paper reports computational simulations in support of arc-jet panel testing capability development using semi-elliptical nozzles in a high enthalpy arc-jet facility at NASA Ames Research Center. Two different semi-elliptical nozzle configurations are proposed for testing panel test articles. Computational fluid dynamics simulations are performed to provide estimates of achievable panel surface conditions and useful test area for each configuration. The present analysis comprises three-dimensional simulations of the nonequilibrium flowfields in the semi-elliptical nozzles, test box and flowfield over the panel test articles. Computations show that useful test areas for the proposed two nozzle options are $20.32 \mathrm{~cm} \times 20.32 \mathrm{~cm}(8$ in $\times 8$ in) and $43.18 \mathrm{~cm} \times 43.18 \mathrm{~cm}(17$ in $\times 17$ in). Estimated values of the maximum cold-wall heat flux and surface pressure are $155 \mathrm{~W} / \mathrm{cm}^{2}$ and $39 \mathrm{kPa}$ for the smaller panel test option, and $44 \mathrm{~W} / \mathrm{cm}^{2}$ and $7 \mathrm{kPa}$ for the larger panel test option. Other important properties of the predicted flowfields are presented, and factors that limit the useful test area in the semi-free jet test configuration are discussed.
\end{abstract}

\section{Nomenclature}

$a_{e} \quad=$ half-width of the semi-elliptical nozzle exit, $\mathrm{cm}$

$a_{t} \quad=$ half-width of the semi-elliptical nozzle throat, $\mathrm{cm}$

$b_{e} \quad=$ height of the semi-elliptical nozzle exit, $\mathrm{cm}$

$b_{t} \quad=$ height of the semi-elliptical nozzle throat, $\mathrm{cm}$

$c_{i} \quad=$ species mass fraction for species $\mathrm{i}$

$h \quad=$ enthalpy, $\mathrm{MJ} / \mathrm{kg}$

$h_{o} \quad=$ total enthalpy, $\mathrm{MJ} / \mathrm{kg}$

$h_{o b}=$ mass-averaged total enthalpy (or bulk enthalpy), $\mathrm{MJ} / \mathrm{kg}$

$h_{o c l}=$ centerline total enthalpy, $\mathrm{MJ} / \mathrm{kg}$

$h_{o e} \quad=$ boundary-layer edge total enthalpy, $0.995 h_{o}$

$M \quad=$ Mach number

$M_{e} \quad=$ Mach number at boundary layer edge

$\dot{m}=$ mass flow rate, $\mathrm{kg} / \mathrm{s}$

$p \quad=$ pressure, $\mathrm{kPa}$

$p_{b o x} \quad=$ test box pressure, torr

$p_{o} \quad=$ total pressure, $\mathrm{kPa}$

$p_{s} \quad=$ surface pressure, $\mathrm{kPa}$

$q_{w} \quad=$ surface heat flux, $\mathrm{W} / \mathrm{cm}^{2}$

$s=$ arc-length or distance from the plate leading edge location, $\mathrm{m}$

$T=$ temperature or translational-rotational temperature, $\mathrm{K}$

$T_{v} \quad=$ vibrational-electronic temperature, $\mathrm{K}$

$u=$ axial velocity component, $\mathrm{m} / \mathrm{s}$

$\delta \quad=$ boundary layer thickness based on total enthalpy profile, $\mathrm{cm}$

$\rho \quad=$ density, $\mathrm{kg} / \mathrm{m}^{3}$

$\tau_{s} \quad=$ surface shear, $\mathrm{Pa}$

\footnotetext{
" Senior Research Scientist, AMA, Inc., MS 230-2, Associate Fellow AIAA

${ }^{\dagger}$ Facility Research Engineer, Thermo-Physics Facilities Branch, MS 242-8

${ }^{\ddagger}$ Consultant, Jacobs Technology, Inc., MS 229-2
} 


\section{Introduction}

Arc-jet facilities provide the primary means to study the performance of various types of thermal protection systems (TPS) used on the outer surfaces of spacecraft in an aerothermodynamic heating environment. In a high enthalpy arc-jet facility, a test gas, usually air or a mixture of nitrogen, oxygen and argon, is passed through an electric arc discharge where the energy is added to the flow. The test gas is then expanded through a convergingdiverging nozzle into an evacuated test chamber to produce high-enthalpy supersonic or hypersonic flow. NASA Ames Research Center (ARC) has four arc-jet facilities within its Arc-Jet Complex. ${ }^{1}$ Two of these arc-jet facilities, the 20-MW Panel Test Facility (PTF) and 60-MW Interaction Heating Facility (IHF), use semi-elliptical nozzles to produce high-enthalpy flow for panel test articles in a semi-free jet configuration. The 60-MW IHF, producing the highest power rating within the Arc-Jet Complex, was originally constructed for testing of relatively large-scale models at the conditions of the Space Shuttle Orbiter vehicle entry. ${ }^{2-3}$

Two truncated IHF semi-elliptical nozzles (option 1 and option 2) are proposed by the second author to extend the current panel testing capabilities at ARC, specifically to provide the capabilities required for the NASA Orion program and its future TPS testing. The primary objective of this paper is to investigate the feasibility of the two proposed panel test configurations. Panel testing in the semi-elliptical nozzle configuration provides two important advantages over alternative testing using inclined wedge models in conical nozzles: thicker boundary layers over the panel test articles because of the running length starting from the nozzle inlet, and the ability to test much larger panel test articles. Computational fluid dynamics (CFD) simulations are performed to estimate the achievable panel surface conditions and useful test area for each configuration. The present analysis comprises three-dimensional simulations of the nonequilibrium flowfields in the semi-elliptical nozzles, test box and flowfield over the panel test articles.

\section{Arc-Jet Facility and Semi-Elliptical Nozzles}

The IHF consists of a constricted arc heater, a 60-MW DC power supply, interchangeable conical and semielliptical nozzles, a test chamber, and supplementary systems including steam ejector vacuum system, cooling-water system and data acquisition system. The IHF is designed to operate with a set of conical nozzles or a semi-elliptical nozzle at total pressures of 1-9 atm and total bulk enthalpies of 2-28 MJ/kg (air). ${ }^{4}$ The $60-\mathrm{MW}$ constricted arc heater produces high-temperature test gas for both nozzles. Figure 1 shows a photograph of the IHF and its semi-elliptical nozzle inside the test chamber.

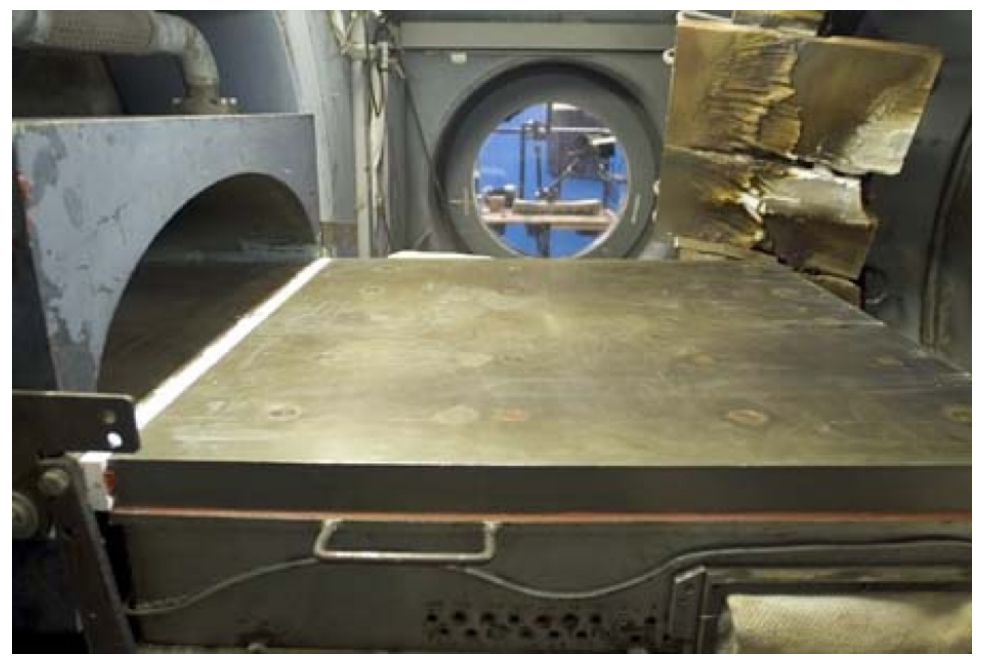

Figure 1. A photograph of the IHF semi-elliptical nozzle test section with a water-cooled calibration plate.

The IHF semi-elliptical nozzle configuration is designed mainly for testing flat panels in hypersonic boundarylayer heating environments. The IHF semi-elliptical nozzle is a converging-diverging nozzle. The converging section starts from a circular shape at the nozzle inlet and transitions into a semi-elliptical shape at the throat (onehalf of an ellipse, with the major axis forming the bottom portion of the nozzle). The diverging section, preserving a semi-elliptical shape, expands conically from the throat to the test section. The nozzle length from the throat is $2.454 \mathrm{~m}(96.625 \mathrm{in})$, and the semi-ellipse parameters ( $\mathrm{a} \mathrm{x} \mathrm{b)} \mathrm{for} \mathrm{the} \mathrm{nozzle} \mathrm{throat} \mathrm{and} \mathrm{exit} \mathrm{cross} \mathrm{sections} \mathrm{are} 6.03 \mathrm{~cm}$ 
x $3.02 \mathrm{~cm}$ (2.375 in x $1.188 \mathrm{in})$ and $40.30 \mathrm{~cm}$ x $20.15 \mathrm{~cm}$ (15.866 in x $7.933 \mathrm{in})$, respectively. The bottom surface of the nozzle includes a high-density ceramic (silfrax) boundary-layer conditioning plate for the last $95 \mathrm{~cm}$ of the nozzle. This provides a hot-wall condition and a boundary-layer profile more typical of flight. Except for the conditioning plate, all of the nozzle walls are water-cooled. Test articles, usually flat panels, are mounted flush to the bottom surface of the nozzle in a supersonic jet at the nozzle exit. Figure 1 shows a photograph of the IHF semielliptical section with a water-cooled calibration plate. The test plate can be deflected from $-5^{\circ}$ to $+9^{\circ}$ with respect to the nozzle bottom surface plane. Positive plate deflection creates a compression ramp at the nozzle exit, resulting in increased surface pressure and heating rates on the test plate. Conversely, negative plate deflection creates a flow expansion at the nozzle exit, reducing pressure and heating rates on the plate surface. The nozzle is fabricated in 1975 in three sections: the present proposal is to split it at these existing junctions to create two new "truncated" (shorter) semi-elliptical nozzles. The two proposed truncated IHF semi-elliptical nozzles options, designated TIHF-1 and TIHF-2, have the following nozzle lengths from the throat and exit cross-section semi-elliptical parameters: $53.67 \mathrm{~cm}(21.129 \mathrm{in})$ and $13.48 \mathrm{~cm} \times 6.74 \mathrm{~cm}(5.308 \mathrm{in} \times 2.654 \mathrm{in})$ for TIHF-1, and $150.6 \mathrm{~cm}(59.304 \mathrm{in})$ and $27.05 \mathrm{~cm} \times 13.58 \mathrm{~cm}$ (10.650 in x $5.345 \mathrm{in})$ for TIHF-2. Further information on the Ames IHF and other arc-jet facilities can be found in Refs. 1-4.

\section{Computational Approach}

Computational analyses of the proposed TIHF semi-elliptical nozzle test configurations are performed through simulation of nonequilibrium expanding flow in the arc-jet nozzle and supersonic jet, and simulation of the flow in the test box and around the test articles. For all CFD calculations, the Data Parallel Line Relaxation (DPLR) code, ${ }^{5,6}$ a NASA Ames in-house flow solver, is used. DPLR has been employed extensively at Ames for hypersonic flight, planetary entry and arc-jet simulations. DPLR provides various options for thermophysical models and formulation. For CFD calculations presented in this paper, three-dimensional Navier-Stokes equations, supplemented with the equations accounting for nonequilibrium kinetic processes, are used in the formulation. The thermochemical model employed for the arc-jet flow includes six species $\left(\mathrm{N}_{2} \mathrm{O}_{2}, \mathrm{NO}, \mathrm{N}, \mathrm{O}, \mathrm{Ar}\right)$ and the thermal state of the gas is described by two temperatures (translational-rotational and vibrational-electronic) within the framework of Park's twotemperature model. ${ }^{7}$

The flowfield in an arc-jet facility, from the arc heater to the test section, is a very complex, three-dimensional flow with various nonequilibrium processes occurring. In order to simulate the flowfield, several simplifying assumptions are made, and corresponding numerical boundary conditions are prescribed for CFD simulations. The present computational approach follows our earlier work used for simulation of other arc-jet facilities, ${ }^{8-12}$ and it is also briefly described here.

Simulations of the IHF arc-jet facility flow with the semi-elliptical nozzles are started from the nozzle inlet. The total enthalpy (and its radial profile) and pressure at the inlet are prescribed, and the flow properties at the inlet are assumed to be in thermochemical equilibrium. Measured facility data, namely, the total pressure (arc-heater plenum pressure), mass flow rate, and test box pressure, are used as boundary conditions. All metallic surfaces, water-cooled nozzle walls, and anodized aluminum calibration plate surfaces are assumed to be fully catalytic to recombination reactions of atomic oxygen and nitrogen at a constant temperature of $500 \mathrm{~K}$. The test box is included in CFD simulations, primarily to account for the free jet expansion formed by the under-expanded flow exiting the nozzle to the test box and its effects on the flowfield over the panel test articles. The jet expansion within the test box is primarily determined by the test box static pressure, which is one of the facility measurements and is prescribed as a boundary condition. Further details of the computational approach can be found in Refs. 8-12.

\section{CFD Simulation Results}

Computational results for the two truncated nozzle options are presented below. These simulations are performed at one facility condition: $p_{\mathrm{o}}=900 \mathrm{kPa}, h_{o b}=26 \mathrm{MJ} / \mathrm{kg}, 5 \%$ argon. Based on the available IHF facility data, this facility condition represents approximately the maximum condition achievable in the IHF in terms of surface pressure and heat flux. The simulations presented in Sections A and B are performed assuming uniform enthalpy profile ath the nozzle inlet. In Section C, simulations using a non-uniform enthalpy profile at the inlet are presented and its effects on the predicted test plate surface quantities are assessed. 


\section{A. TIHF-1: Truncated IHF semi-elliptical nozzle, option 1}

Figure 2 shows computed Mach number contours of the TIHF-1 semi-elliptical nozzle flow with a test plate at zero deflection angle. In Fig. 2a, the Mach number contours are shown on the x-y plane of the nozzle/test box flowfield (symmetry plane) and on three y-z planes: one at the nozzle inlet, one at the nozzle throat, and another at the nozzle exit. The panel test article is located on the $x-z$ plane downstream of the nozzle exit; the leading edge of the panel is at the nozzle exit plane. The predicted frozen Mach number at the TIHF-1 nozzle exit is 2.37 . Due to the nonequilibrium expansion process in arc-jet nozzles, the chemical composition freezes near the throat where the flow is dissociated and vibrationally excited. As shown in Fig. 2b, because of the relatively low expansion ratio for the TIHF-1, for this condition, the computations predict that the flow is not yet chemically frozen, and it is in vibrational equilibrium or thermal equilibrium before it reaches the nozzle exit. Note that oxygen remains fully dissociated within the entire flowfield except in the boundary layer near the walls, while nitrogen is partially dissociated. Also note that the expansion waves emanating from the corner of the nozzle exit connected to the test box are clearly observed in the computed Mach number contours. Boundary layer profiles of various flow quantities

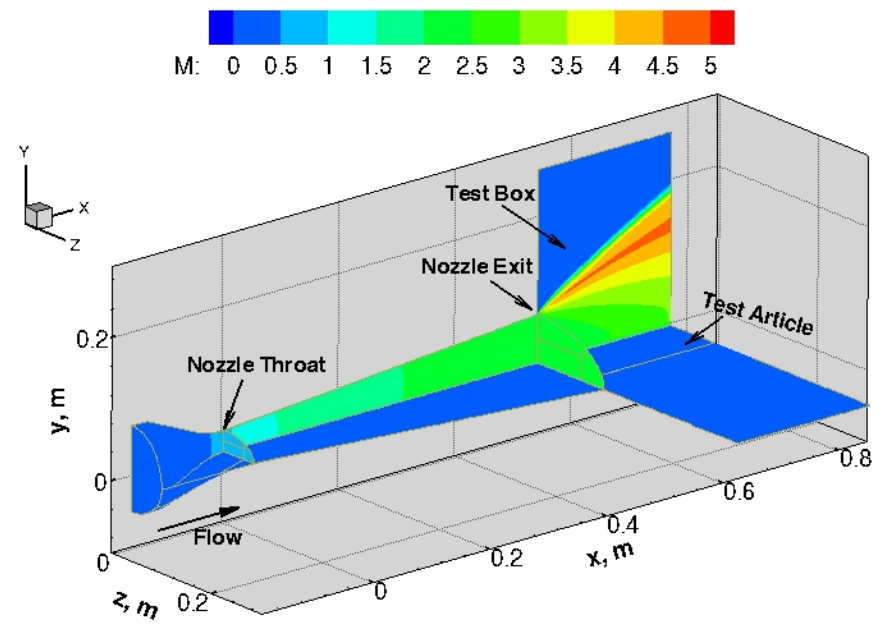

a) Mach number contours

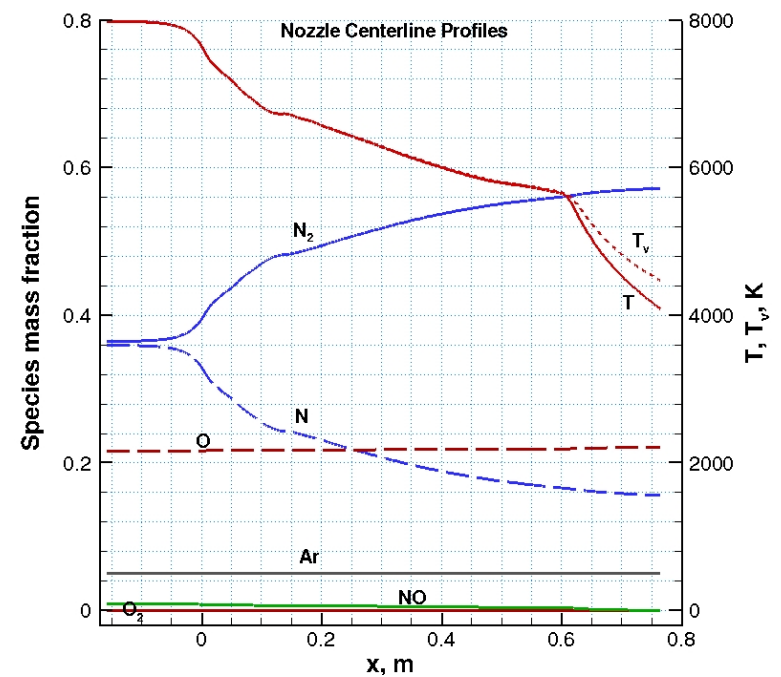

(b) nozzle centerline

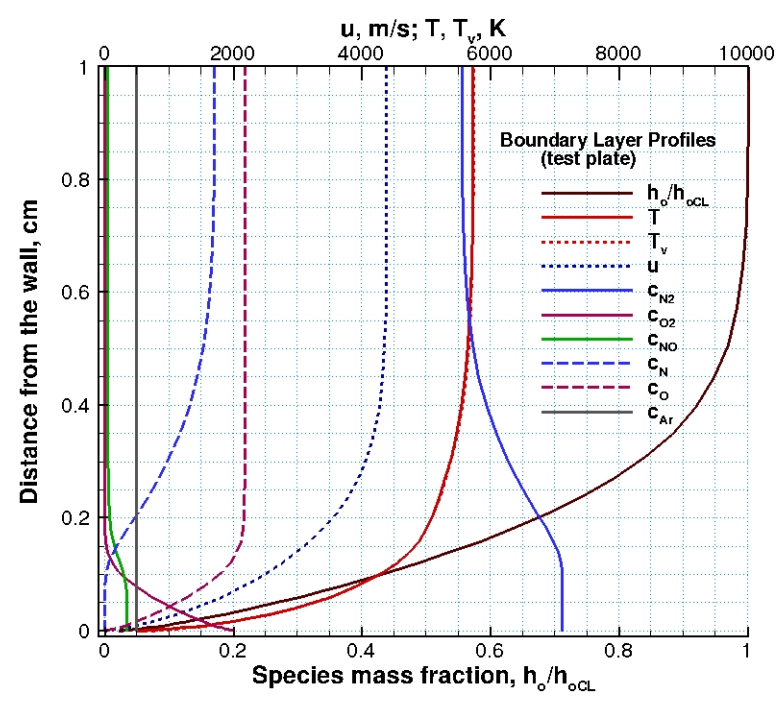

(c) boundary layer profiles at $\mathrm{x}=0.545 \mathrm{~m}$

Figure 2. Computed flowfield of the TIHF-1 semi-elliptical nozzle including the test box and panel test article. $p_{o}=900 \mathrm{kPa}, h_{o}=26 \mathrm{MJ} / \mathrm{kg}, 5 \% \mathrm{Ar}, p_{b o x}=20$ torr. 

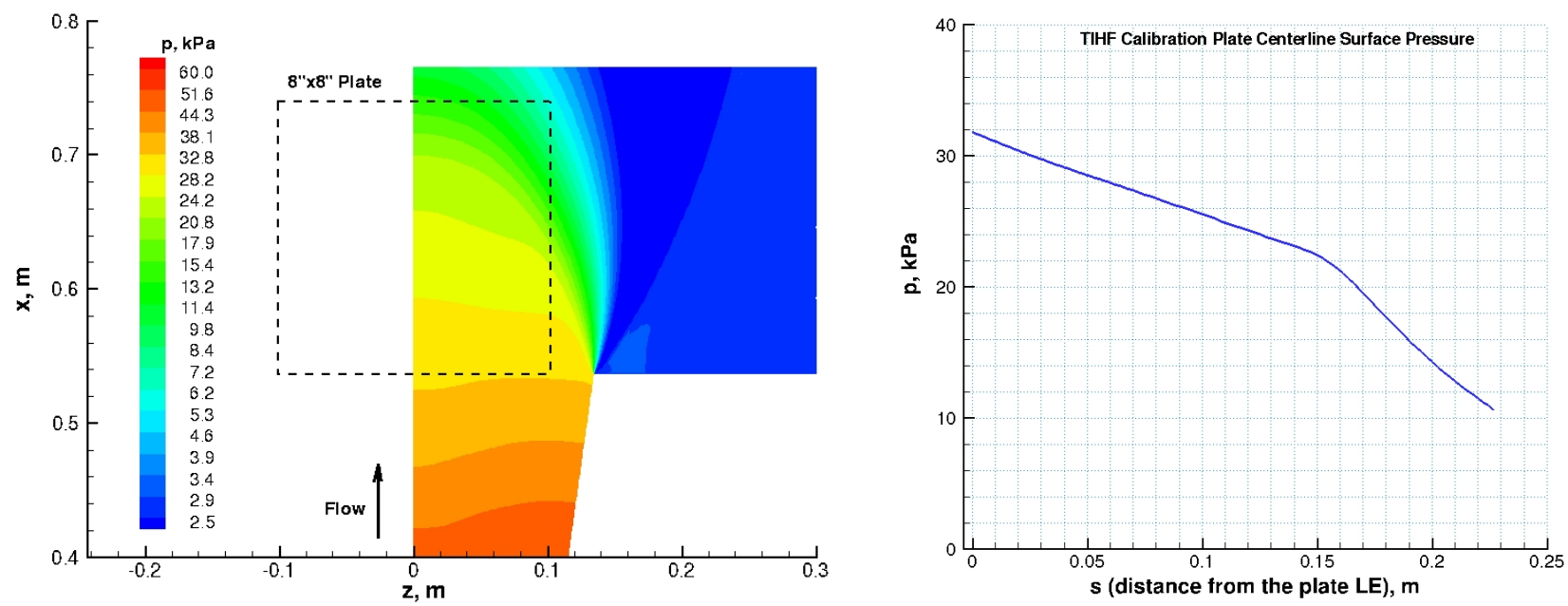

(a) pressure
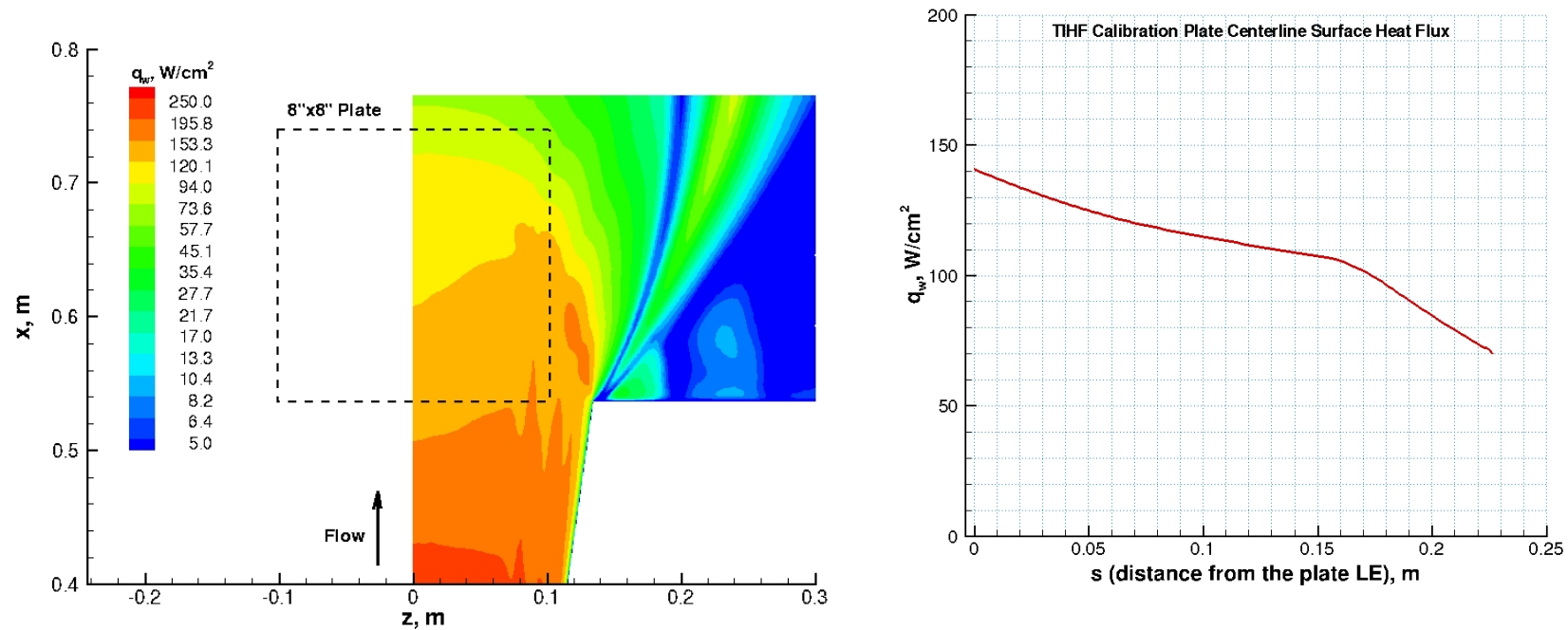

(b) heat flux
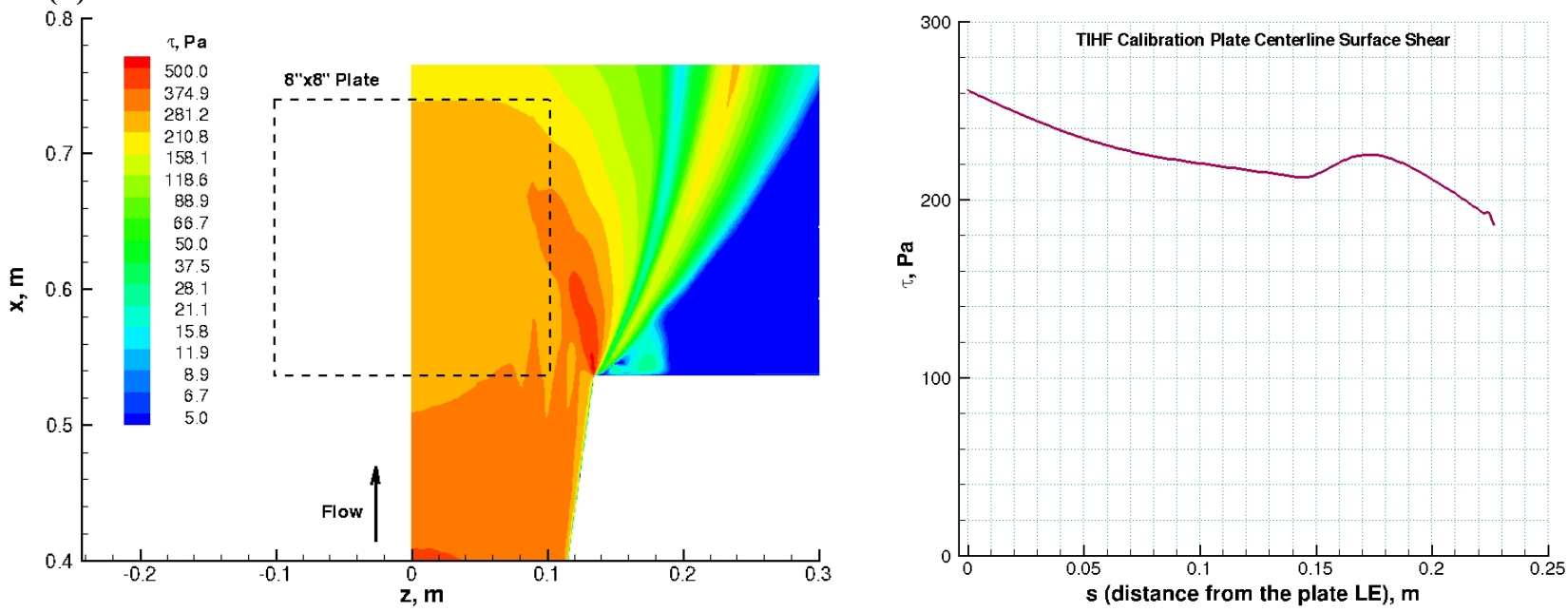

(c) shear

Figure 3. Computed contours of surface quantities of the TIHF-1 calibration plate and their centerline profiles at zero plate deflection. $p_{o}=900 \mathrm{kPa}, h_{o}=h_{o b}=26 \mathrm{MJ} / \mathrm{kg}, 5 \% \mathrm{Ar}, p_{b o x}=20$ torr. 
$\mathrm{x}=0.545 \mathrm{~m}$ location are shown in Fig. $2 \mathrm{c}$. The estimated boundary layer thickness at this location is $0.69 \mathrm{~cm}$ (based on the total enthalpy profile from the wall).

Figure 3 shows computed surface quantities of the water-cooled calibration plate. The contour plots show computed surface pressure, heat flux and shear on one half of the calibration plate, and the line plots show the corresponding profiles along the plate centerline. The computed pressure and heating distributions on the watercooled plate are typical of those observed in a semi-free jet expansion. ${ }^{9-12}$ Both pressure and heat flux on the plate decrease away from the nozzle exit as the flow exiting the nozzle continues to expand. Since the test box pressure is lower than the nozzle exit pressure (under-expanded nozzle flow), the flow continues to expand after exiting the nozzle. The expansion waves emanating from the nozzle exit into the test box interact with the flow over the test plate thus affecting the distributions of pressure and heat flux on the plate surface. The computations predict that a panel area of approximately $20.32 \mathrm{~cm} \times 20.32 \mathrm{~cm}$ ( 8 in $\times 8$ in) is not significantly affected by the expansion waves. The predicted surface pressure, heat flux and shear ranges along the plate centerline are $31.8-13.8 \mathrm{kPa}, 140.8-83.1$ $\mathrm{W} / \mathrm{cm}^{2}$, and 262-210 Pa, respectively. The useful test area is loosely defined as the panel test area in which gradients of test article surface quantities (heat flux, pressure and shear) are acceptable for evaluation of TPS performance. Clearly, high shear regions on each side near the nozzle exit should be avoided in testing and evaluation of any TPS samples. Also, if the surface pressure gradients were critically important for certain tests, then the test panel could be limited to a smaller area of $20.32 \mathrm{~cm} \mathrm{x} 15.24 \mathrm{~cm}(8 \mathrm{in} \times 6$ in).
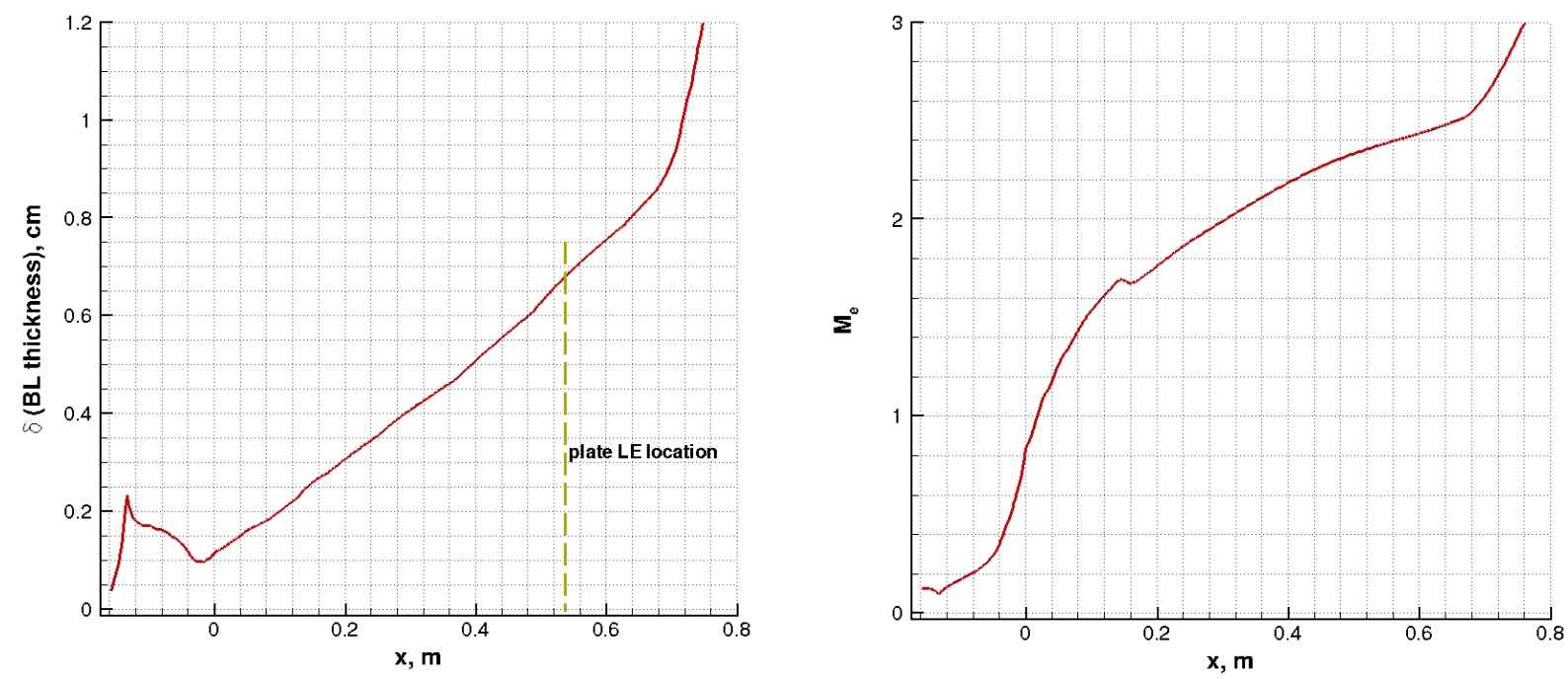

Figure 4. Computed boundary layer thickness and edge Mach number along TIHF-1 semi-elliptical nozzle and test plate centerline at zero plate deflection. $p_{o}=900 \mathrm{kPa}, h_{o}=h_{o b}=26 \mathrm{MJ} / \mathrm{kg}, 5 \% \mathrm{Ar}, p_{b o x}=20$ torr.

One of the advantages of this panel test configuration (e.g., in comparison with an alternative panel test using an inclined wedge model) is that the flow over the test article has a significant boundary layer thickness because of the running length starting from the nozzle inlet. The boundary layer thickness and boundary layer edge Mach number become important test parameters when the panel test articles include surface features such as gaps and protuberances. Figure 4 shows the distributions of the predicted boundary layer thickness and edge Mach number along the TIHF-1 nozzle and plate centerline at zero deflection. For a high enthalpy reacting flow, several boundary layer thicknesses can be defined in terms of momentum, temperature, enthalpy, and species concentrations, etc. However, as there are flowfield gradients in all of these quantities (e.g. see Fig. 2c), the total enthalpy profile normal to the wall is used to detect the boundary layer edge. As one marches away from the wall, the location at which $h_{o e}=$ $0.995 h_{o}$ is determined as the boundary layer edge. Clearly, this definition is an approximation and an attempt to provide a consistent boundary layer thickness estimate of a high enthalpy flow for engineering analysis.

As mentioned earlier, in this semi-free jet test configuration, the test plate can be deflected with respect to the nozzle bottom surface plane, and a positive plate deflection creates a compression ramp at the nozzle exit, resulting in increased surface pressure and heating rates on the test plate. Figure 5 shows the computed flowfield contours 
near the TIHF-1 semi-elliptical nozzle exit with $4^{\circ}$ deflection. Computed Mach number contours show the oncoming supersonic flow and its interaction with the flow over the deflected panel article. This interaction of the supersonic boundary layer flow and leading edge shock wave causes the flow to separate at the leading edge due to the adverse pressure gradient. However, the extent of the separation is minimal at this small plate deflection. The contours are shown on the symmetry plane of the nozzle and test box flowfield (x-y plane) and on the bottom surface of the nozzle and test plate (x-z plane). The pressure contours in Fig. 5b clearly show that the expansion waves emanating from the corner of the nozzle exit connected to the test box interact with the incoming flow over the plate. This flow interaction, with the exit Mach number and plate deflection angle being the most important parameters, ultimately determines the useful test area in this semi-free jet test configuration.

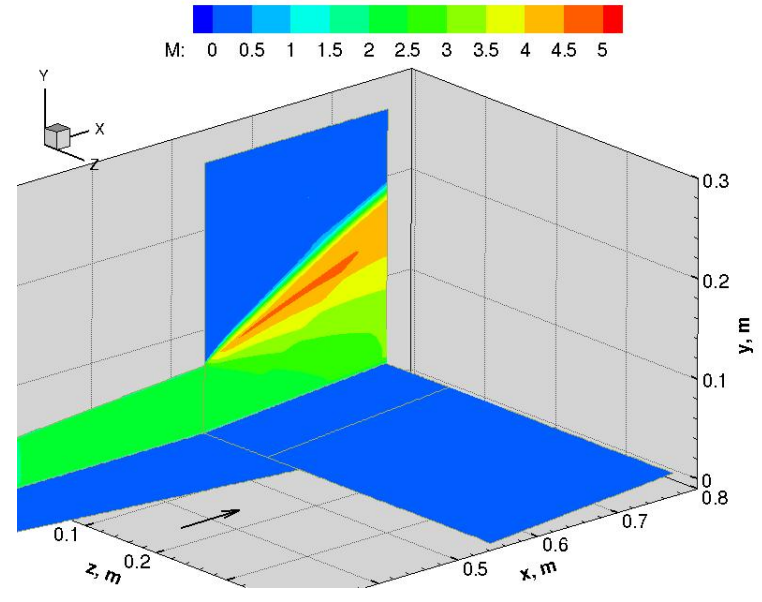

(a) Mach number

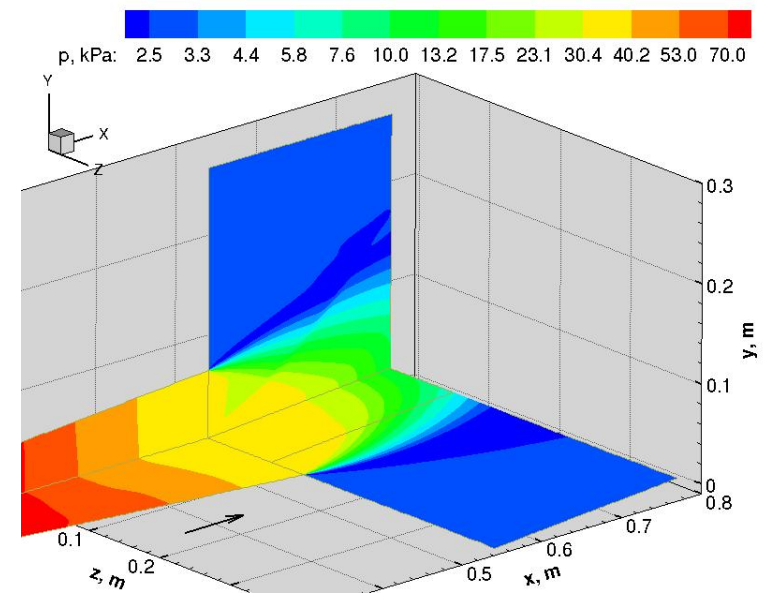

(b) pressure

Figure 5. Computed contours of the flowfield near the TIHF-1 semi-elliptical nozzle exit and over the calibration plate at $4^{\circ}$ deflection angle. $p_{o}=900 \mathrm{kPa}, h_{o}=h_{o b}=26 \mathrm{MJ} / \mathrm{kg}, 5 \% \mathrm{Ar}, p_{b o x}=20 \mathrm{torr}$.

In Fig. 6, computed surface quantities of the water-cooled calibration plate at $4^{\circ}$ deflection angle are presented. Although the trends observed are similar to those seen in Fig. 3 for the zero deflection case, pressure, heat flux and shear levels are all increased due to the $4^{\circ}$ plate deflection. It should be noted that the start of the wave interaction location on the test plate surface has moved upstream, and the gradients in surface pressure and heat flux in the interaction region are larger (Fig. 6a-b vs. Fig. 3a-b). For TIHF-1, plate deflections larger than $4^{\circ}$ are not recommended because the interaction region is moving upstream with increasing deflection angle, thus reducing the useful panel test area. Not including the small separated region at the plate leading edge, the predicted surface pressure, heat flux and shear ranges along the plate centerline are $39.4-14.5 \mathrm{kPa}, 155.2-88.9 \mathrm{~W} / \mathrm{cm}^{2}$, and $253-226 \mathrm{~Pa}$, respectively. These effects in surface quantities are modest ( $24 \%$ increase in pressure, $10 \%$ increase in heat flux, and $3-4 \%$ decrease in shear) primarily because of the relatively small nozzle exit Mach number (2.37) and relatively small plate deflection. 

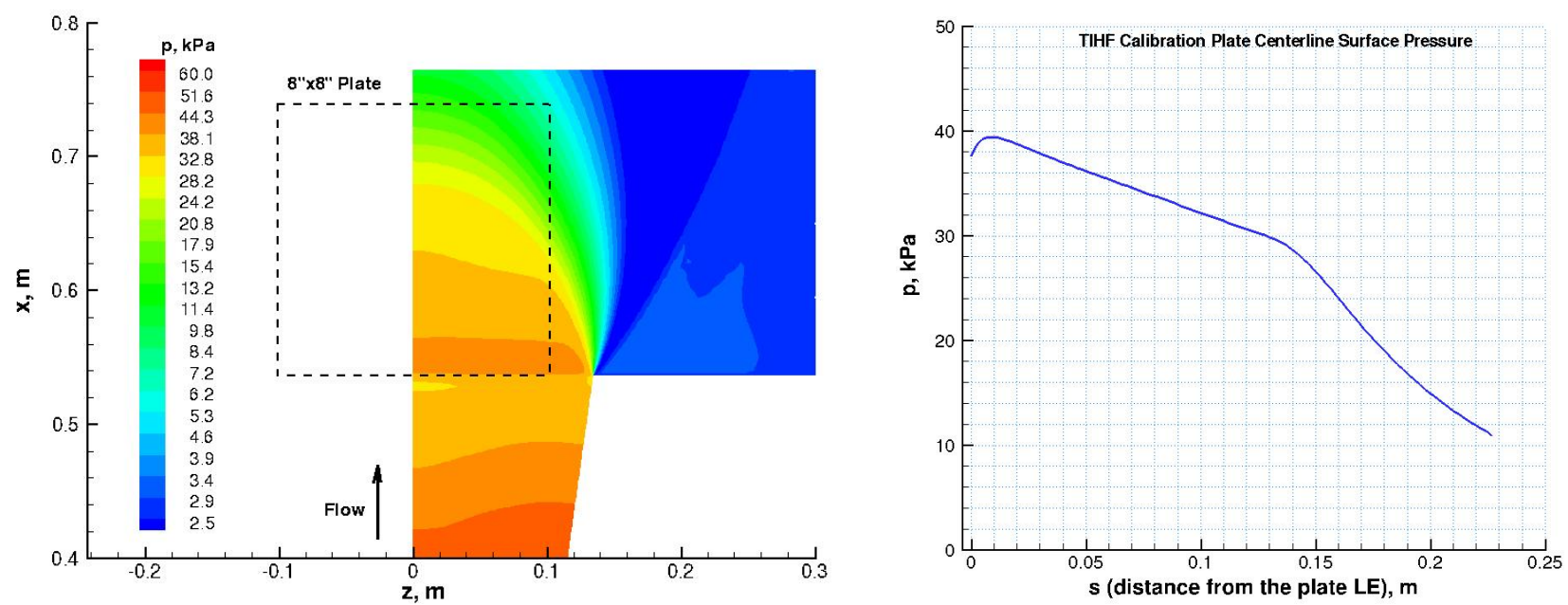

(a) pressure
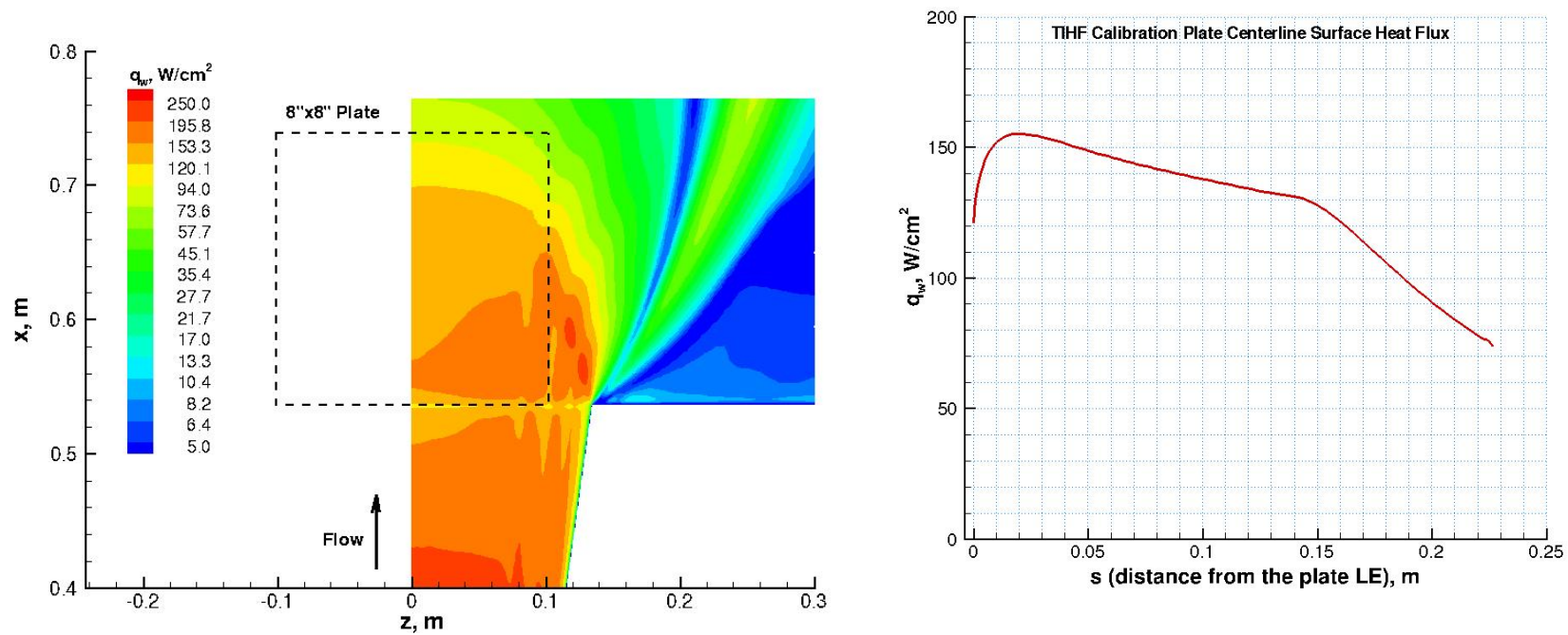

(b) heat flux
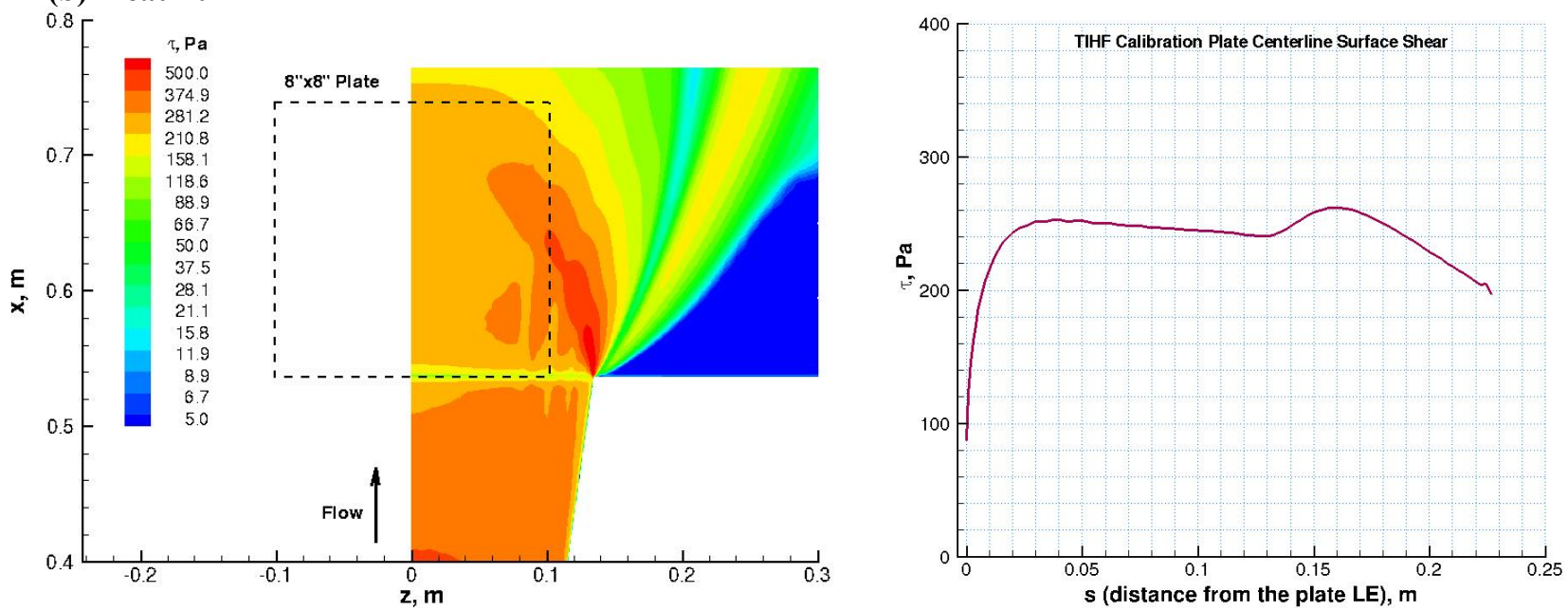

(c) shear

Figure 6. Computed contours of surface quantities of the TIHF-1 calibration plate and their centerline profiles at $4^{\circ}$ plate deflection. $p_{o}=900 \mathrm{kPa}, h_{o}=h_{o b}=26 \mathrm{MJ} / \mathrm{kg}, 5 \% \mathrm{Ar}, p_{b o x}=20$ torr. 


\section{B. TIHF-2: Truncated IHF semi-elliptical nozzle, option 2}

Figure 7 shows computed Mach number contours of the TIHF-2 semi-ellptical nozzle flow with a test plate at zero deflection angle. Similar to Fig. 2a for TIHF-1, in Fig. 7a, the Mach number contours are shown on the x-y plane of the nozzle/test box flowfield (symmetry plane) and on three y-z planes: one at the nozzle inlet, one at the nozzle throat, and another at the nozzle exit. The panel test article is similarly located on the x-z plane downstream of the nozzle exit. The predicted frozen Mach number at the TIHF-2 nozzle exit is 3.47 . Figure $7 \mathrm{~b}$ shows flowfield variables along the nozzle centerline and in a boundary layer over the test plate. In contrast with Fig. $2 \mathrm{~b}$, for the TIHF-2 nozzle, the computations predict that the flow is chemically frozen and remains in thermal equilibrium before it reaches the nozzle exit. Also, note that because of much longer running length for TIHF-2, the flow over the test article has a substantially thicker boundary layer. The estimated boundary layer thickness at $\mathrm{x}=1.525 \mathrm{~m}$ location is $2.17 \mathrm{~cm}$.

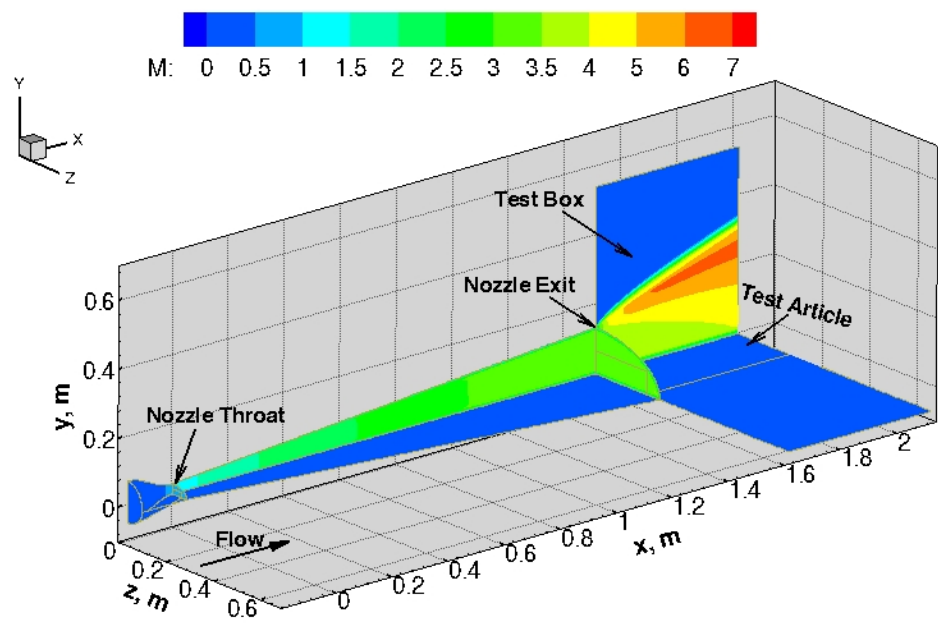

a) Mach number contours

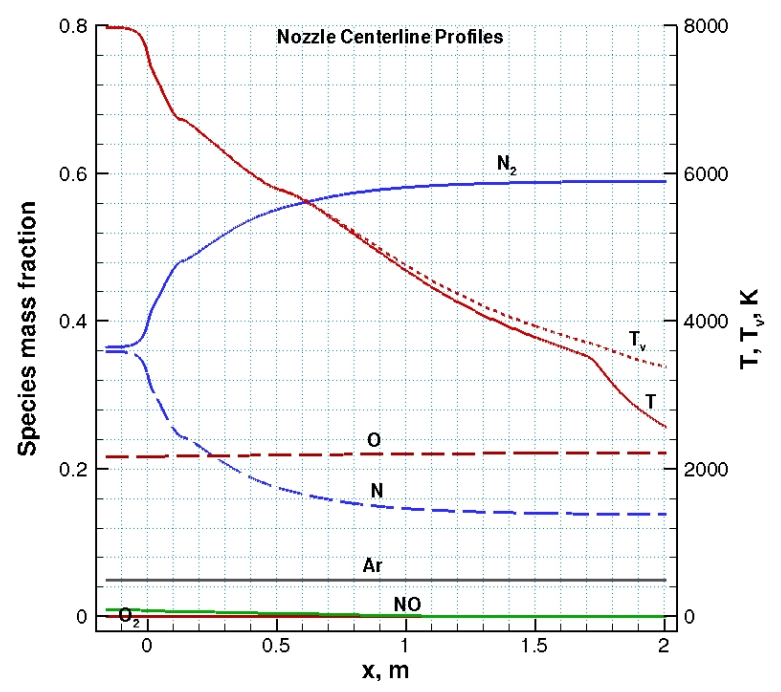

(b) nozzle centerline

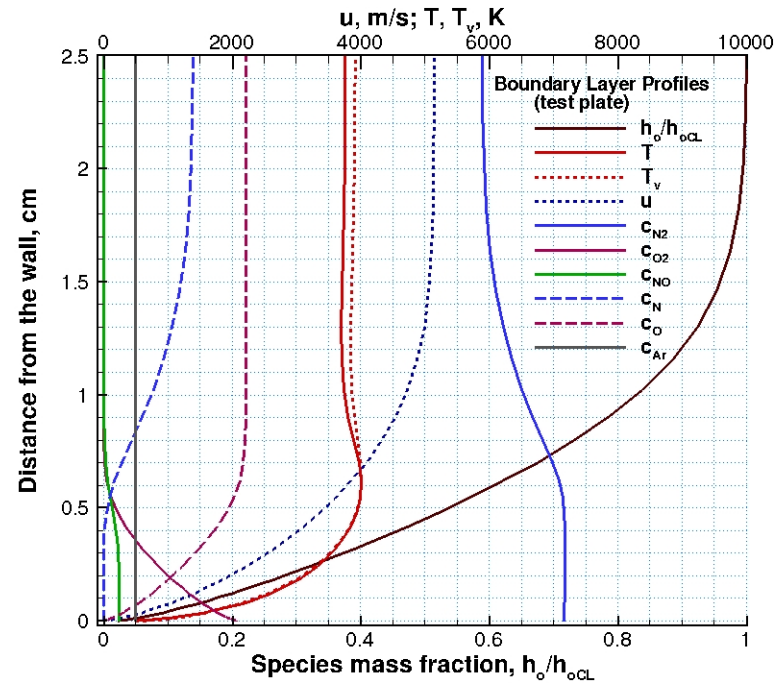

(c) boundary layer profiles at $x=1.525 \mathrm{~m}$

Figure 7. Computed flowfield of the TIHF-2 semi-elliptical nozzle including the test box and panel test article: $p_{o}=900 \mathrm{kPa}, h_{o}=h_{o b}=26 \mathrm{MJ} / \mathrm{kg}, 5 \% \mathrm{Ar}, p_{b o x}=4$ torr. 

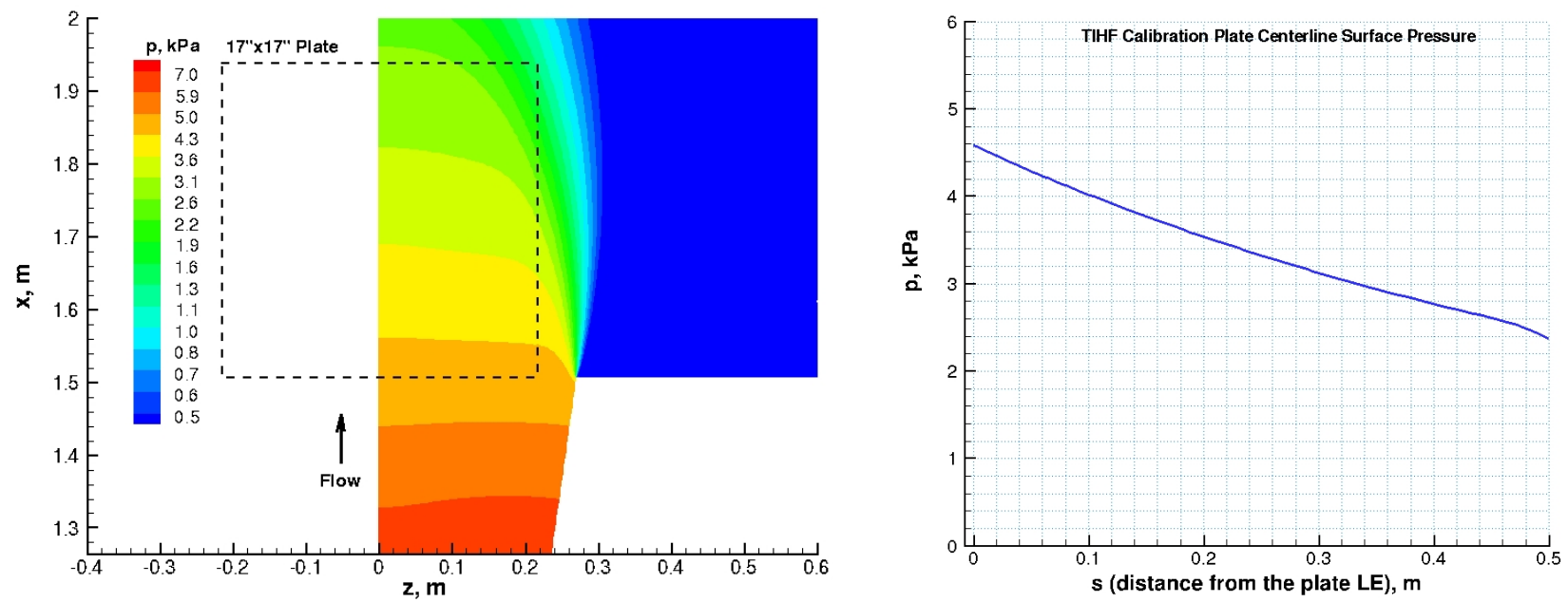

(a) pressure
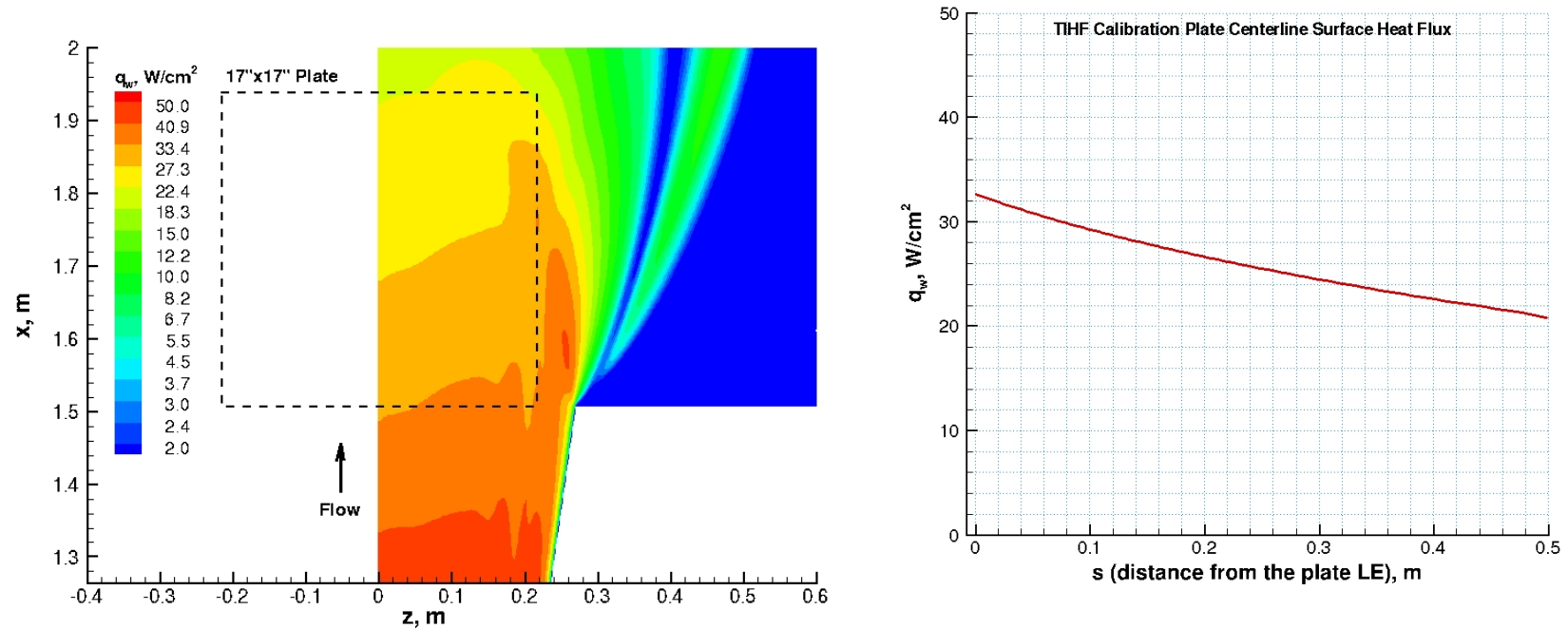

(b) heat flux
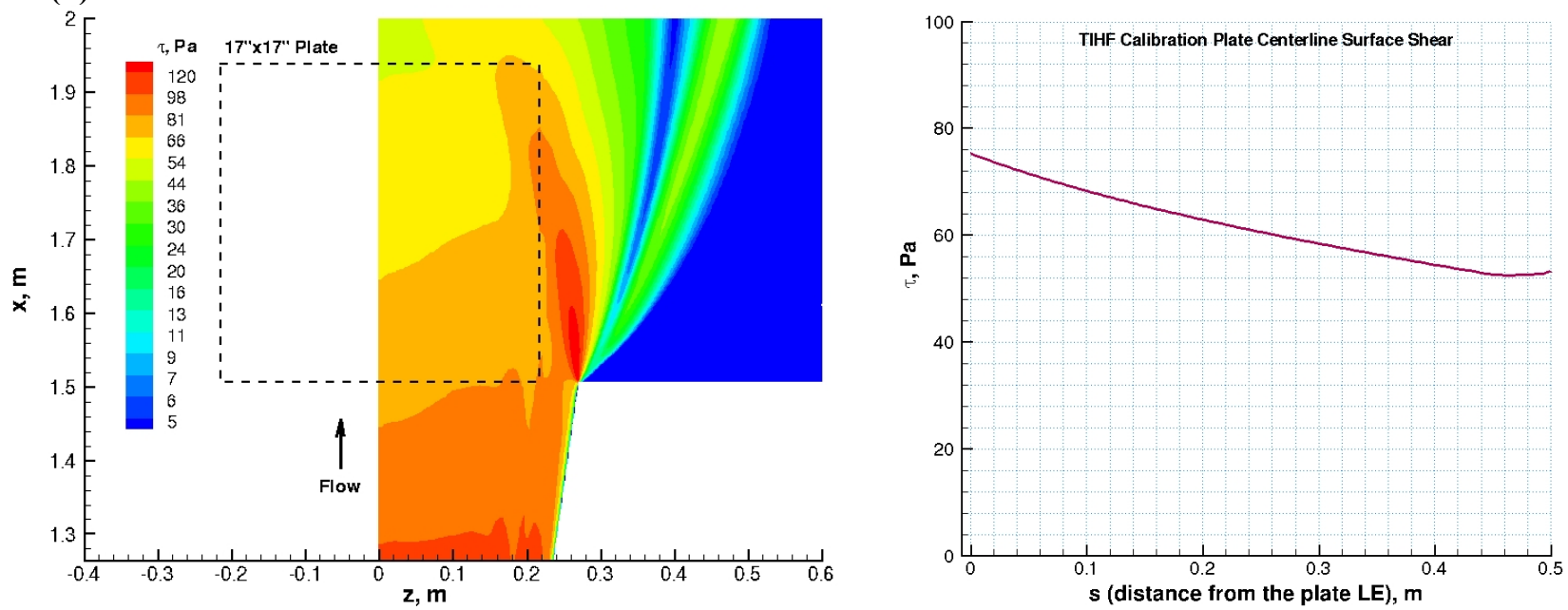

(c) shear

Figure 8. Computed contours of surface quantities of the TIHF-2 calibration plate and their centerline profiles at zero plate deflection. $p_{o}=900 \mathrm{kPa}, h_{o}=h_{o b}=26 \mathrm{MJ} / \mathrm{kg}, 5 \% \mathrm{Ar}, p_{b o x}=4$ torr. 
Figure 8 shows computed surface quantities of the TIHF-2 water-cooled calibration plate. Again, the contour plots show computed surface pressure, heat flux and shear on one half of the plate, and the line plots show the corresponding profiles along the plate centerline. The computations predict that a panel area of approximately $43.18 \mathrm{~cm} \mathrm{x} 43.18 \mathrm{~cm}$ (17 in $\times 17$ in) is relatively unaffected by the nozzle expansion wave interactions. The predicted surface pressure, heat flux and shear ranges along the plate centerline are $4.59-2.66 \mathrm{kPa}, 32.7-22.0 \mathrm{~W} / \mathrm{cm}^{2}$, and 75.4-53.2 $\mathrm{Pa}$, respectively.

Figure 9 shows the distributions of the predicted boundary layer thickness and edge Mach number along the TIHF-2 nozzle and plate centerline at zero plate deflection. Note that because of much longer running length for the TIHF-2 and flow expansion, the flow over the test article has a substantially thicker boundary layer (over $2 \mathrm{~cm}$ ), and the Mach number at the nozzle exit is about 3.5 .
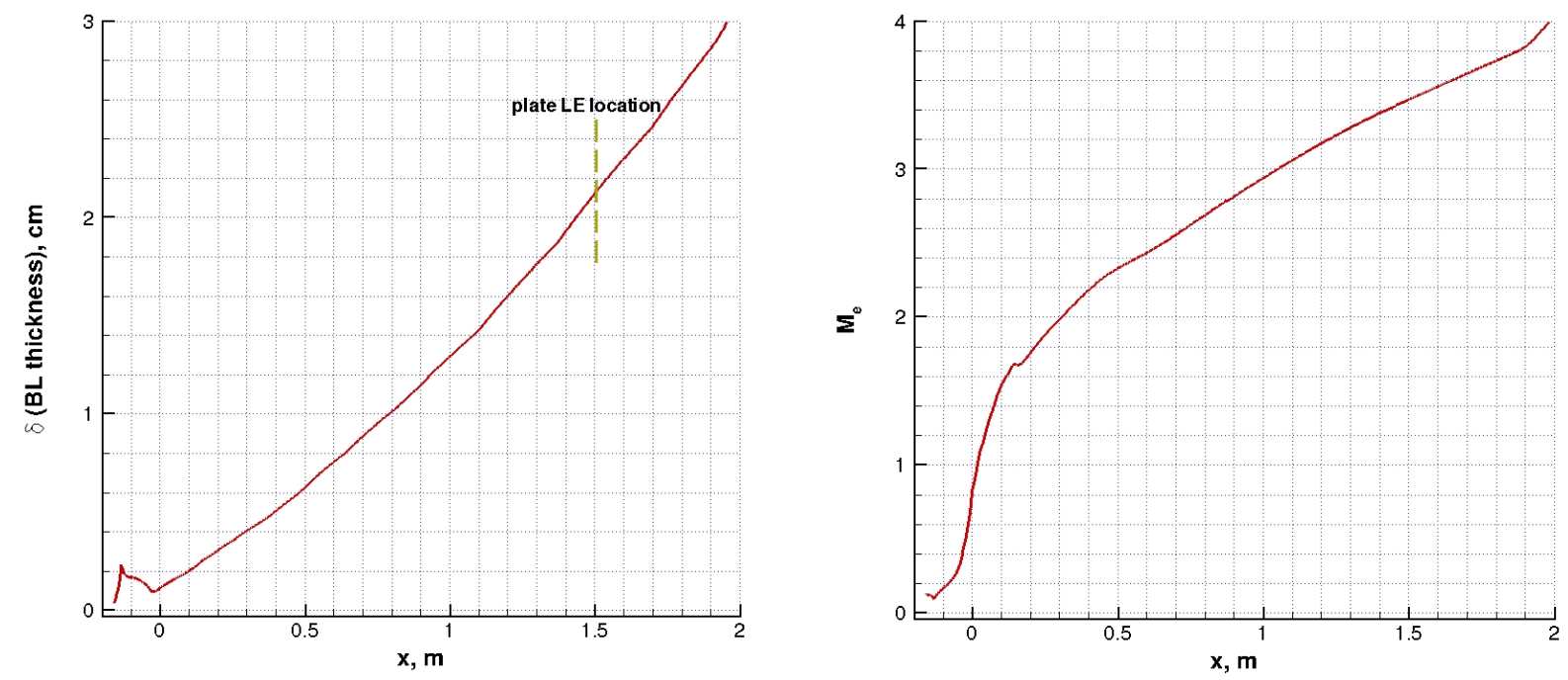

Figure 9. Computed boundary layer thickness and edge Mach number along TIHF-2 semi-elliptical nozzle and test article centerline at zero plate deflection. $p_{o}=900 \mathrm{kPa}, h_{o}=h_{o b}=26 \mathrm{MJ} / \mathrm{kg}, 5 \% \mathrm{Ar}, p_{\text {box }}=4 \mathrm{torr}$.

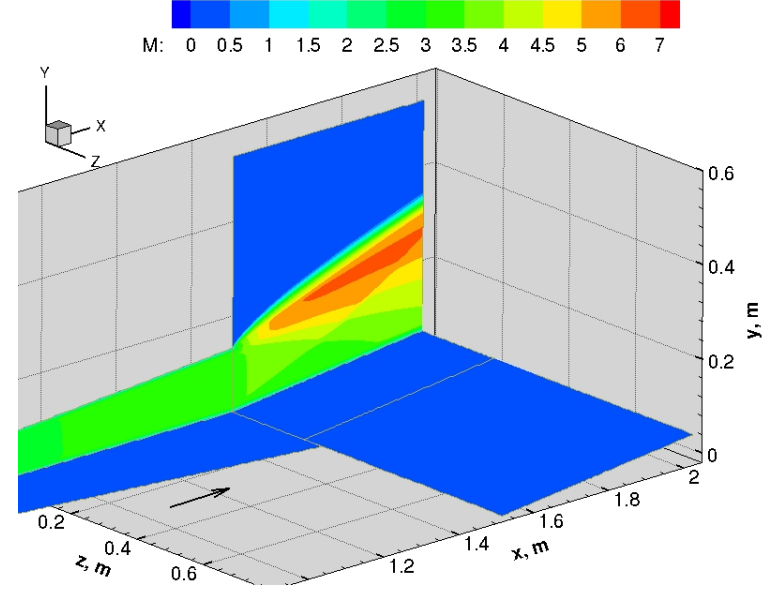

(a) Mach number

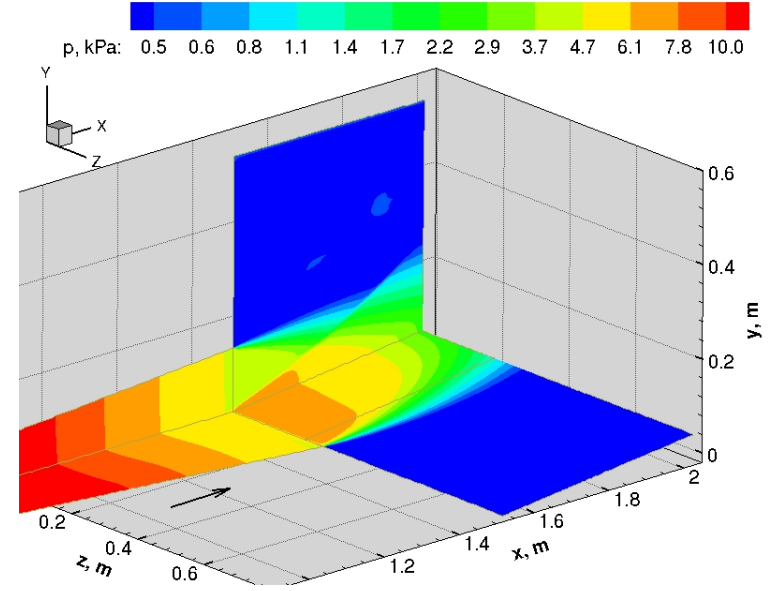

(b) pressure

Figure 10. Computed contours of the flowfield near the TIHF-2 semi-elliptical nozzle exit and over the calibration plate at $6^{\circ}$ deflection angle: $p_{o}=900 \mathrm{kPa}, h_{o}=h_{o b}=26 \mathrm{MJ} / \mathrm{kg}, 5 \% \mathrm{Ar}, p_{b o x}=4 \mathrm{torr}$.

Figure 10 shows the computed flowfield contours near the TIHF-2 semi-elliptical nozzle exit with $6^{\circ}$ plate deflection. Computed Mach number contours show the on-coming supersonic flow and its interaction with flow over 

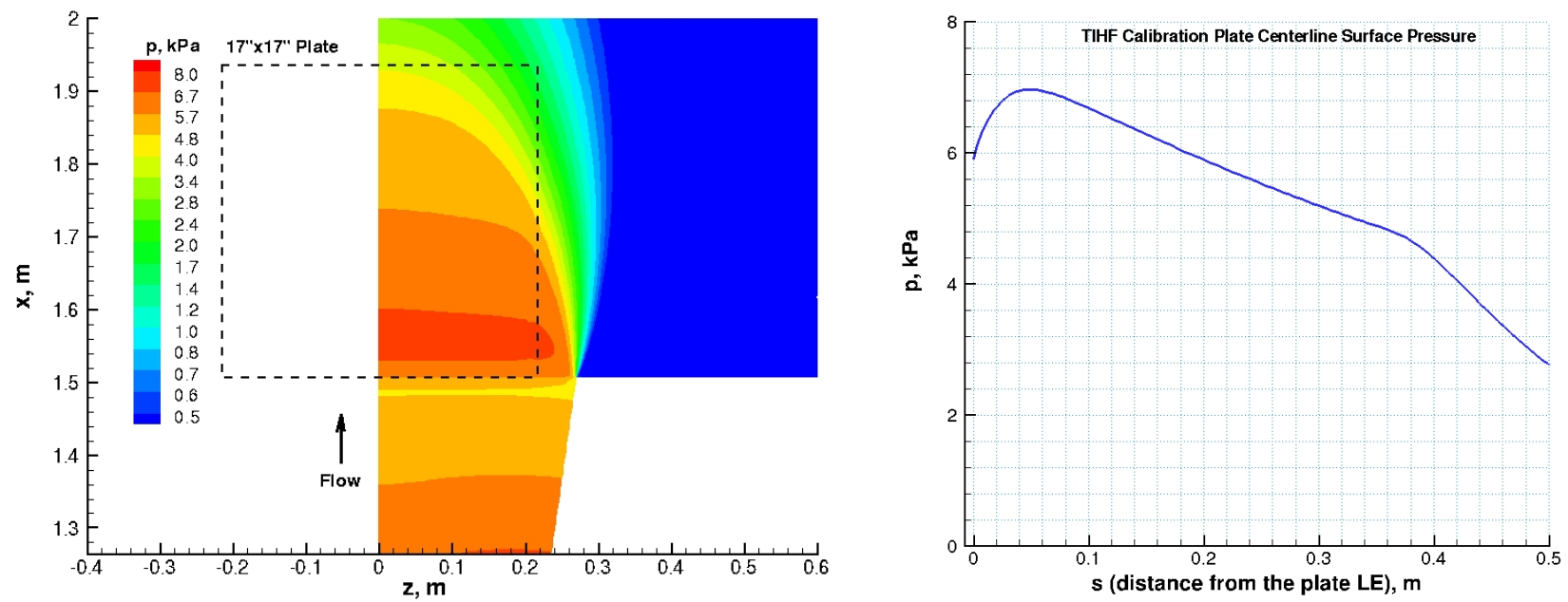

(a) pressure
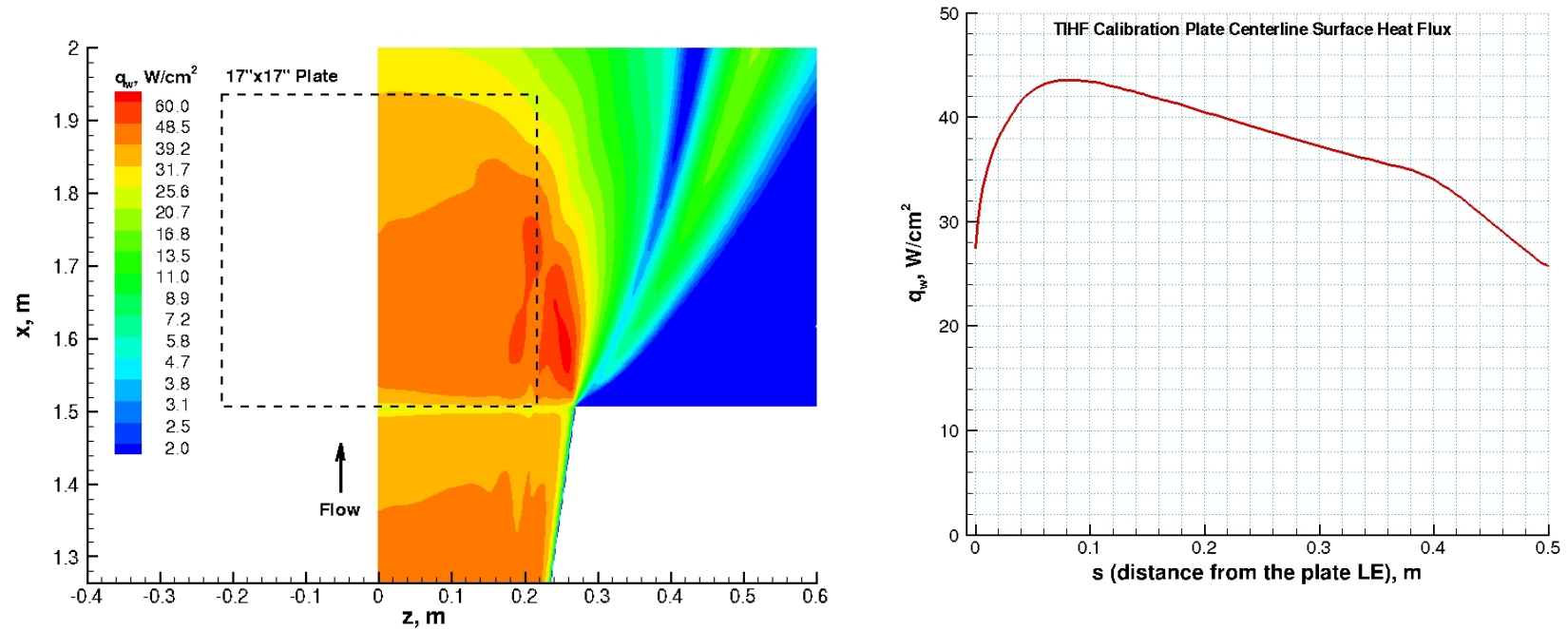

(b) heat flux
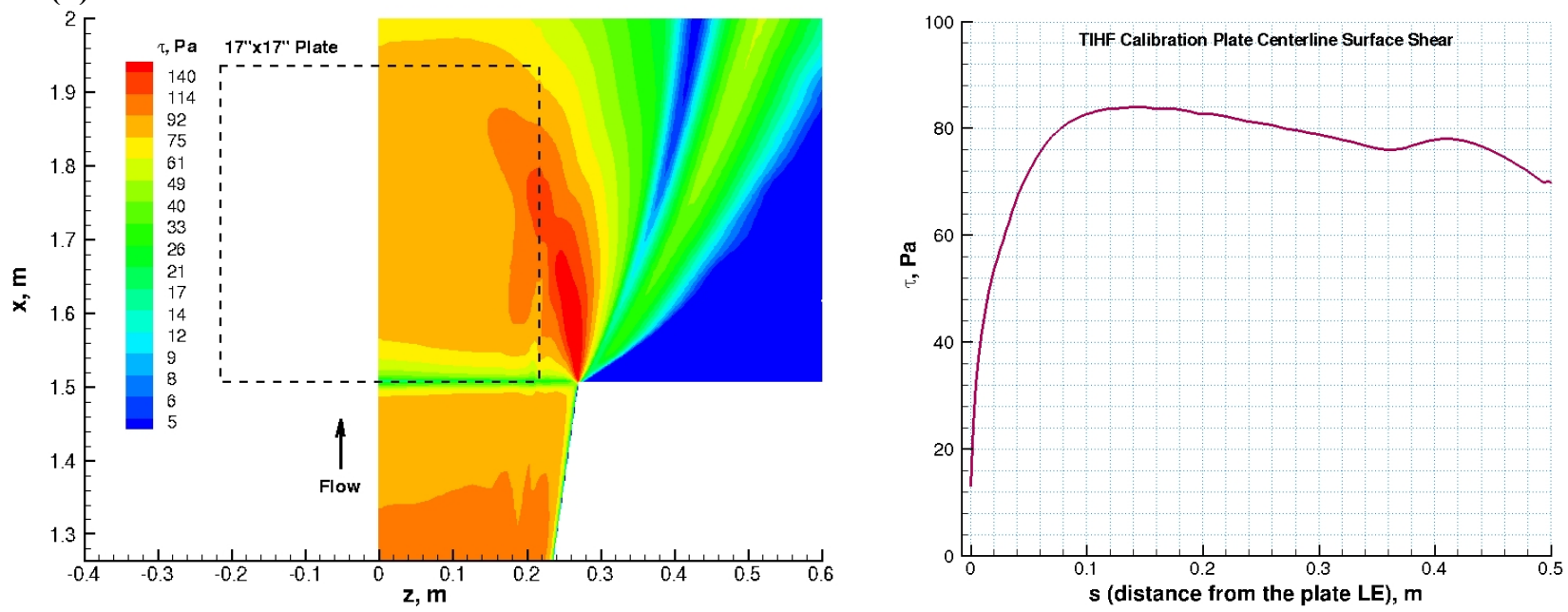

(c) shear

Figure 11. Computed contours of surface quantities of the TIHF-2 calibration plate and their centerline profiles at $6^{\circ}$ plate deflection. $p_{o}=900 \mathrm{kPa}, h_{o}=h_{o b}=26 \mathrm{MJ} / \mathrm{kg}, 5 \% \mathrm{Ar}, p_{b o x}=4$ torr. 
the deflected panel test article. Since the exit Mach number is larger for the TIHF-2 nozzle than for the TIHF-1 nozzle, the effect of the expansion wave flow interaction on the plate surface quantities is felt further downstream from the nozzle exit. For the same reason, it is also possible to have a larger plate deflection angle of $6^{\circ}$ in the THIF-2 without seeing adverse effects of the expansion wave flow interaction.

In Fig. 11, computed surface quantities of the TIHF-2 water-cooled calibration plate at $6^{\circ}$ deflection angle are presented. Again, not including the small separated region at the plate leading edge, the predicted surface pressure, heat flux and shear ranges along the plate centerline are $6.96-3.80 \mathrm{kPa}, 43.6-31.4 \mathrm{~W} / \mathrm{cm}^{2}$, and $84.1-77.1 \mathrm{~Pa}$, respectively. Note that because of the higher Mach number at the TIHF-2 nozzle exit and larger plate deflection, the increases obtained in the plate surface pressure and heat flux are much larger, about $52 \%$ in pressure and $33 \%$ in heat flux.

\section{Effects of Non-Uniform Enthalpy Profile on Predicted Surface Quantities}

The extent of flow non-uniformity at the nozzle exit can be assessed through detailed pitot pressure and heat flux surveys of the flow exiting the nozzle, resulting in an inferred total enthalpy profile that can be used at the nozzle inlet. There are no such surveys available yet for the IHF semi-elliptical nozzle. Based on the available facility data (and limited pitot/heat flux surveys) obtained using the IHF conical nozzles, the flow non-uniformity at the maximum facility condition (maximum current and pressure, without any cold gas injection at the arc-heater plenum) is expected to be minimal. Again, based on the historical facility and calorimeter data for various IHF conical nozzles, the maximum centerline enthalpy inferred through CFD simulations is estimated to be about 29.5 $\mathrm{MJ} / \mathrm{kg}$. In order to assess the effect of flow non-uniformity on the predicted surface quantities, TIHF-1 and TIHF-2 simulations are performed assuming a parabolic enthalpy profile and uniform pressure at the nozzle inlet, keeping the total pressure and bulk enthalpy values the same at $900 \mathrm{kPa}$ and $26 \mathrm{MJ} / \mathrm{kg}$.

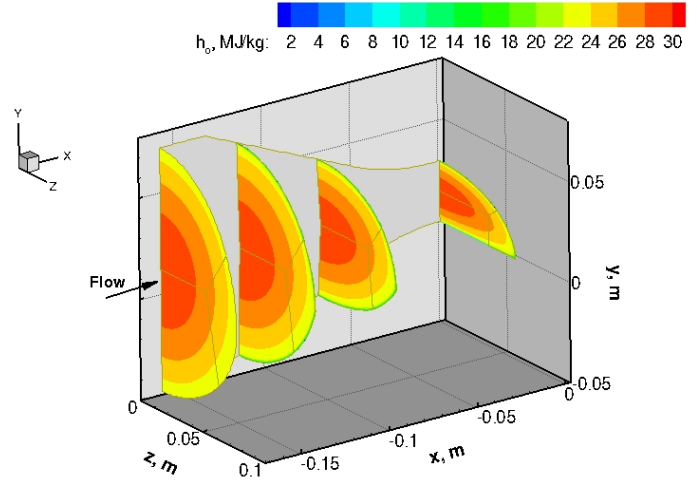

(a) total enthalpy

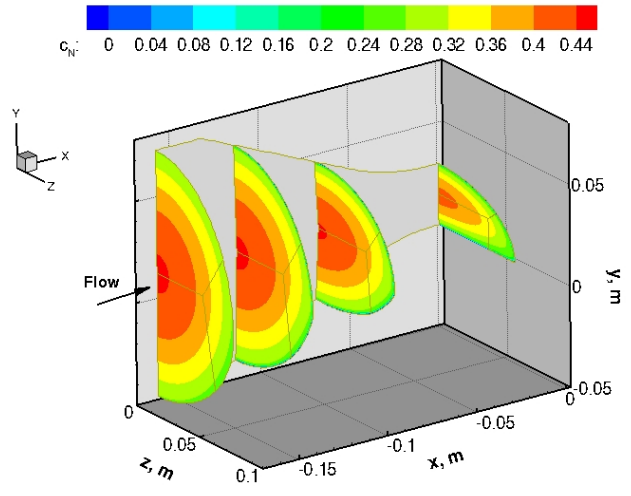

(b) atomic nitrogen mass fraction

Figure 12. Computed flowfield contours at selected stations in the subsonic section of the semi-elliptical nozzles (TIHF-1 and TIHF-2), from the nozzle inlet (circular) to the throat (semi-elliptical). $p_{o}=900 \mathrm{kPa}$, parabolic enthalpy profile, $h_{o b}=26 \mathrm{MJ} / \mathrm{kg}, h_{o c l}=29.5 \mathrm{MJ} / \mathrm{kg}, 5 \% \mathrm{Ar}$.

Figure 12 shows computed flowfield contours of total enthalpy and atomic nitrogen mass fraction in the subsonic section of the TIHF-1 and TIHF-2 nozzles (or IHF semi-elliptical nozzle, all have identical subsonic flow section). The total enthalpy and $\mathrm{N}$ mass fraction contours are shown at four axial locations from the circular nozzle inlet section to the semi-elliptical throat section. Due to the significant differences in the enthalpy profiles, in comparison with the uniform enthalpy simulations presented in Figs. 2-11, it is expected that there would be significant differences in the flowfield chemistry in the nozzle. However, although the flowfield chemistry is altered with the non-uniform enthalpy profile, its overall effect on computed surface quantities of the calibration plate (or test plate) is somewhat secondary. Figures 13 and 14 show computed surface quantities of the TIHF-1 and TIHF-2 watercooled calibration plates, respectively. Again, the contour plots show computed surface pressure, heat flux and shear on one half of the plate, and the line plots show the corresponding profiles along the plate centerline. For the TIHF-1 

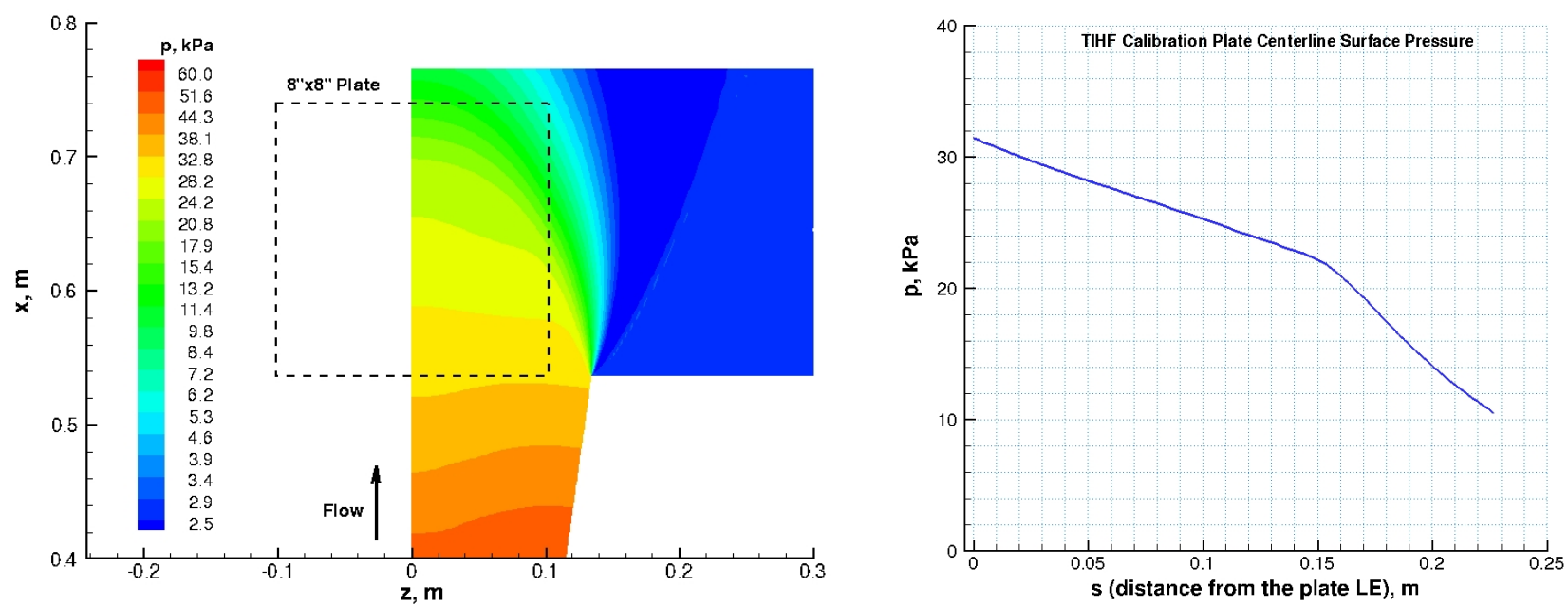

(a) pressure
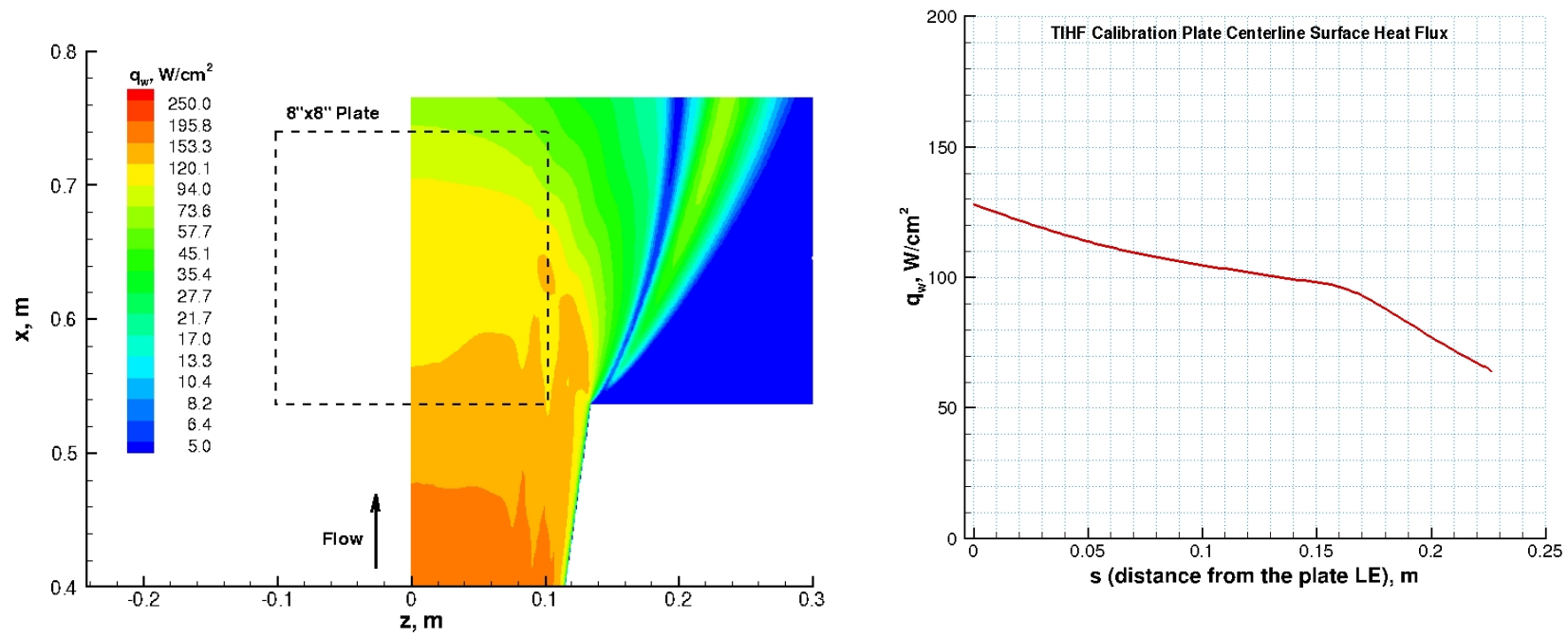

(b) heat flux
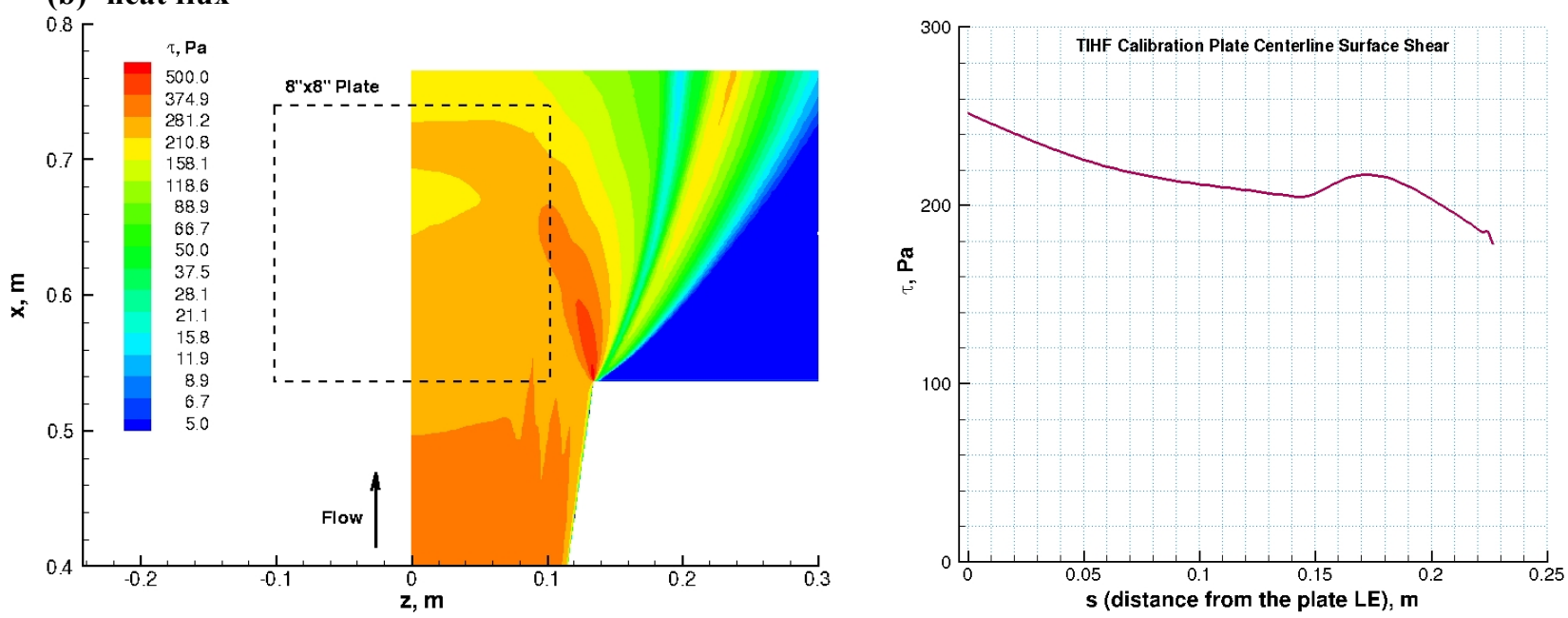

(c) shear

Figure 13. Computed contours of surface quantities of the TIHF-1 calibration plate and their centerline profiles at zero plate deflection. $p_{o}=900 \mathrm{kPa}$, parabolic enthalpy profile, $h_{o b}=26 \mathrm{MJ} / \mathrm{kg}, h_{o c l}=29.5 \mathrm{MJ} / \mathrm{kg}, 5 \% \mathrm{Ar}$, $p_{b o x}=20$ torr. 

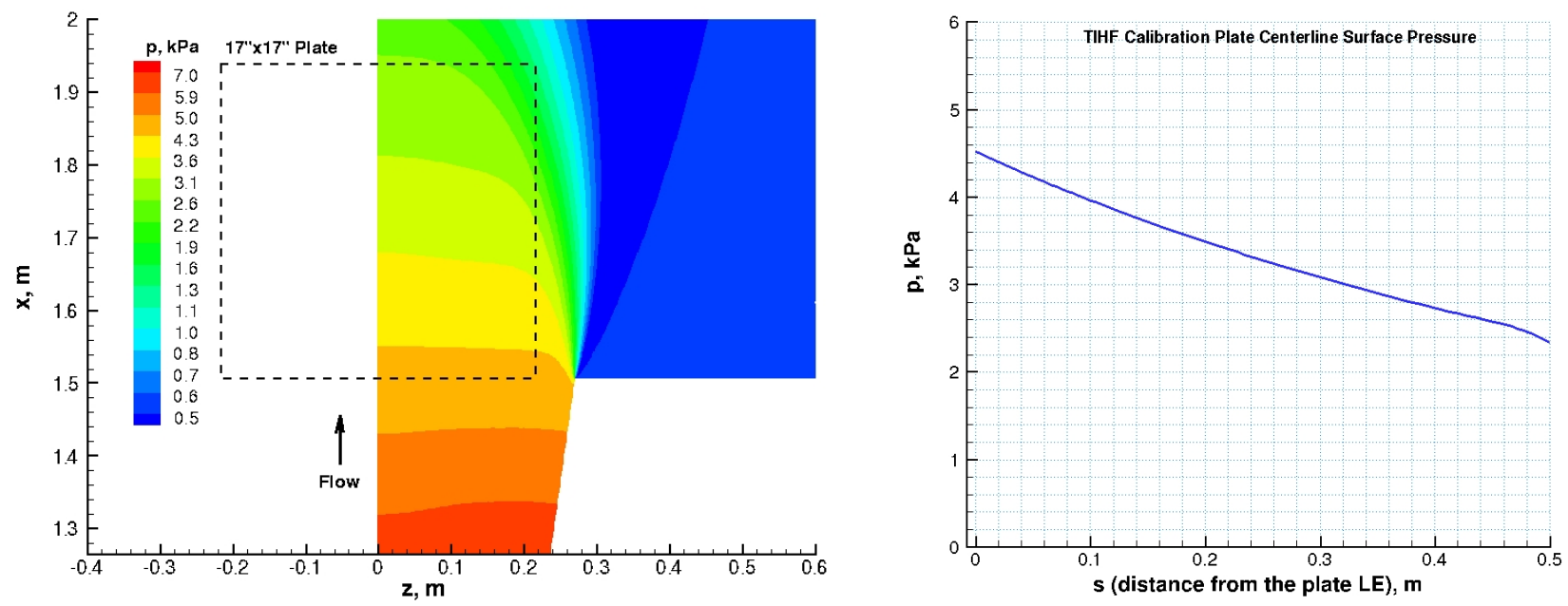

(a) pressure
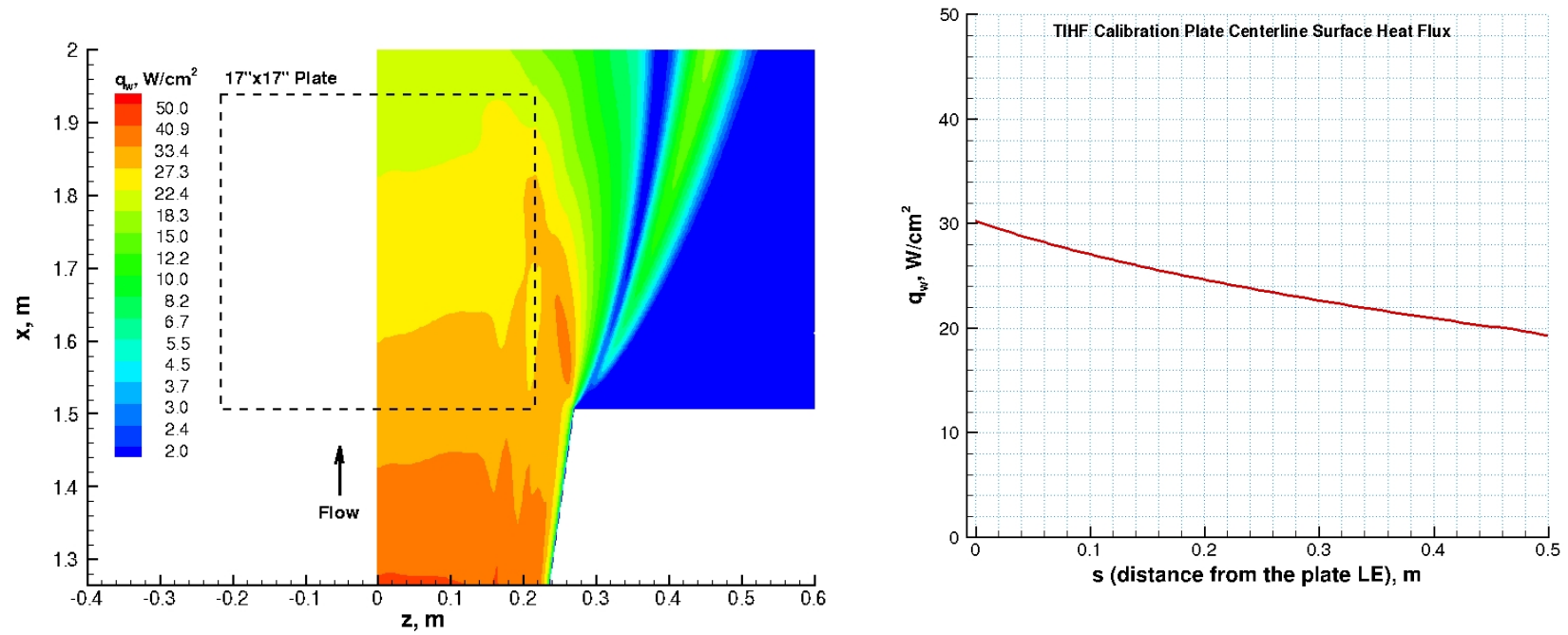

(b) heat flux
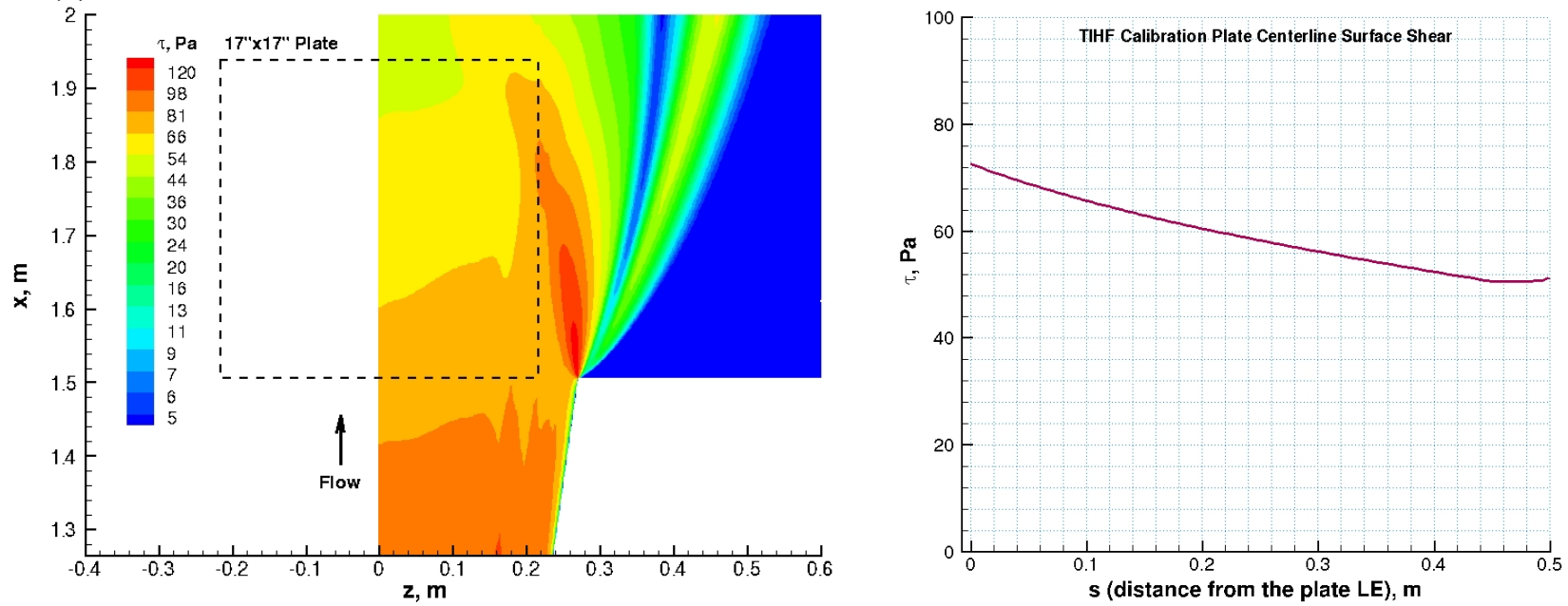

(c) shear

Figure 14. Computed contours of surface quantities of the TIHF-2 calibration plate and their centerline profiles at zero plate deflection. $p_{o}=900 \mathrm{kPa}$, parabolic enthalpy profile, $h_{o b}=26 \mathrm{MJ} / \mathrm{kg}, h_{o c l}=29.5 \mathrm{MJ} / \mathrm{kg}, 5 \% \mathrm{Ar}$, $p_{b o x}=4$ torr. 
plate ( 8 in $x 8$ in size), the predicted surface pressure, heat flux and shear ranges along the plate centerline are 31.5 13.7 $\mathrm{kPa}, 128.2-75.9 \mathrm{~W} / \mathrm{cm}^{2}$, and 252-202 Pa, respectively. For the TIHF-2 plate (17 in $\mathrm{x} 17$ in), the predicted surface pressure, heat flux and shear ranges along the plate centerline are $4.52-2.63 \mathrm{kPa}, 30.2-20.4 \mathrm{~W} / \mathrm{cm}^{2}$, and $72.7-$ 51.2 Pa, respectively. In comparison with the simulations using uniform properties at the nozzle inlet (Figs. 3 and 8 for TIHF-1 and TIHF-2, respectively) with the same bulk enthalpy and total pressure, the surface heat flux is most affected and reduced as much as $9 \%$. These results are consistent with our earlier simulations of the PTF semielliptical nozzle flow, ${ }^{7}$ which concluded that the computed heat flux levels and distribution are not very sensitive to the enthalpy profile, and that increasing the centerline to bulk enthalpy ratio reduces the plate surface heat flux, but only slightly.

\section{Computational Grid Details and Estimated Uncertainties}

The three-dimensional CFD computations of the truncated semi-elliptical nozzle flowfields including the test box were performed using multi-block grids. For the TIHF-1 simulations, an 11-block grid with 5.62 million cells was used; and for the TIHF-2 simulations, an 11-block grid with 6.12 million cells was used. The number of cells from the nozzle inlet to the test plate exit was 540 for the TIHF-1 and 600 for the TIHF-2, with 120 cells normal to the wall along the nozzle and 210 over the panel test article. Based on a limited number of grid refinement studies (and a more detailed grid refinement study for similar PTF semi-elliptical nozzle simulations in Ref. 11), the grid quality issues of the computations and numerical accuracy were adequately addressed.

However, CFD computations of arc-jet flows, as for hypersonic flight simulations, include uncertainties in many of the model input parameters. It is not possible at this time to do a complete uncertainty analysis of computed results for all of the simulation input parameters. The most important input parameter of the arc-jet test flow is the total enthalpy (and its distribution) at the nozzle inlet. For the semi-free jet test configuration in the TIHF-1 and TIHF-2, the computed test plate surface quantities are found to be not very sensitive to the flow enthalpy nonuniformity expected in the IHF at the maximum facility condition (see Section C). Also, in our earlier work for similar semi-elliptical nozzle simulations, ${ }^{8,11}$ reasonably good agreement was found between the laminar CFD computations and calibration plate measurements. Nevertheless, considering the uncertainty in the bulk enthalpy input and other modeling input parameters, the estimated uncertainty in the laminar heat flux predictions for the TIHF-1 and TIHF-2 calibration plates is estimated to be as much as $\pm 20 \%$. The uncertainty in surface pressure predictions is estimated to be $\pm 5-10 \%$. Ultimately, the water-cooled calibration plates with distributed heat flux and pressure gages should be built for each TIHF facility in order to verify these CFD estimates.

\section{Summary and Concluding Remarks}

The feasibility of the two proposed panel test configurations using truncated IHF semi-ellliptical nozzles is investigated. Computational simulations show that the truncation option 1 can provide a testing capability for test articles as large as $20.32 \mathrm{~cm} \times 20.32 \mathrm{~cm}$ ( 8 in $\times 8$ in) while the option 2 should accommodate test articles as large as $43.18 \mathrm{~cm} \mathrm{x} 43.18 \mathrm{~cm}$ (17 in x $17 \mathrm{in})$. For testing option 1, estimated values of the maximum cold-wall heat flux and surface pressure are $141 \mathrm{~W} / \mathrm{cm}^{2}$ and $32 \mathrm{kPa}$ at zero plate deflection, and $155 \mathrm{~W} / \mathrm{cm}^{2}$ and $39 \mathrm{kPa}$ at $4^{\circ}$ plate deflection. For testing option 2, estimated values are $33 \mathrm{~W} / \mathrm{cm}^{2}$ and $4.6 \mathrm{kPa}$ at zero plate deflection, and $44 \mathrm{~W} / \mathrm{cm}^{2}$ and $7.0 \mathrm{kPa}$ at $6^{\circ}$ plate deflection.

In the semi-free jet test configuration, expansion waves emanating from the corner of the nozzle exit connected to the test box, and their interaction with the incoming flow over the plate, play important roles. The present CFD simulations take into account these effects in order to predict heating levels and distribution over the test plates. This flow interaction, with the exit Mach number and plate deflection angle being the most important parameters, ultimately determines the useful test area in this test configuration. The computations show that although positive plate deflection angle increases the testing capabilities in terms of the plate surface pressure and heat flux for each facility, it is recommended that this angle should not exceed $4^{\circ}$ for the TIHF- 1 and $6^{\circ}$ for the TIHF- 2 because the expansion wave interactions reduce the area of uniform surface conditions. For larger plate deflection angles, the useful test area for each facility would be reduced, mostly in the streamwise direction. The benefit of constructing these truncated semi-elliptical nozzles is that they will provide distinct advantages over alternative wedge testing in conical nozzles, such as thicker boundary layers over the panel test articles and the ability to test much larger panel test articles. 


\section{Acknowledgments}

This work was funded by the NASA Orion LEAF-Lite project and NASA Ames Entry Systems and Technology Division, through contract NNA15BB15C to AMA, Inc.

\section{References}

${ }^{1}$ Terrazas-Salinas, I., and the staff of Thermophysics Facilities Branch, "Test Planning Guide for NASA Ames Research Center Arc-Jet Complex and Range Complex," A029-9701-XM3 Rev. C, Entry Systems and Technology Division, NASA Ames Research Center, April 2009.

${ }^{2}$ Winovich, W., and Carlson, W., "The 60-MW Shuttle Interaction Heating Facility," $25^{\text {th }}$ ISA Symposium, May 1979.

${ }^{3}$ Winovich, W., Balakrishnan, A., and Balboni, J., "Experimental and Analytical Derivation of Arc-Heater Scaling Laws for Simulating High-Enthalpy Environments for Aeroassisted Orbital Transfer Vehicle Application," AIAA Paper 85-1006, June 1985.

${ }^{4}$ Fretter, E., "Interaction Heating Facility (IHF) Fact Sheet," http://www.nasa.gov/centers/ames/thermophysicsfacilities-home, Thermophysics Facilities Branch, Entry Systems and Technology Division, NASA Ames Research Center, Jan. 2015.

${ }^{5}$ Wright, M. J., Candler, G. V., and Bose, D., "Data-Parallel Line Relaxation Method for the Navier-Stokes Equations," AIAA Journal, Vol. 36, No. 9, 1998, pp. 1603-1609.

${ }^{6}$ Wright, M. J., “Data-Parallel Line Relaxation Code, DPLR Version 4.02,” Private Communication, June 2010.

${ }^{7}$ Park, C., Nonequilibrium Hypersonic Aerothermodynamics, John Wiley \& Sons, Inc., New York, 1990, Chap. 4.

${ }^{8}$ Gökçen, T., and Stewart, D. A., "Computational Analysis of Semi-elliptical Nozzle Arc-jet Experiments: Calibration Plate, Wing Leading Edge," AIAA Journal, Vol. 45, No. 1, Jan. 2007, pp. 128-137; also AIAA Paper 2005-4887, June 2005.

${ }^{9}$ Balboni, J. A., Gökçen, T., Hui, F. C. L., Taunk, J., Noyes, E., and Schickele, D., "Calibration of the Truncated Panel Test Arc-Jet Facility,” AIAA Paper 2009-4090, June 2009.

${ }^{10}$ Gökçen, T., Alunni, A. I., and Skokova, K. A., "Computational Simulations of Panel Test Facility Flow: Compression-Pad Arc-Jet Tests,” AIAA Paper 2011-3635, June 2011.

${ }^{11}$ Gökçen, T., and Alunni, A. I., "On Laminar-to-Turbulent Transition of Arc-Jet Flow in the NASA Panel Test Facility," Journal of Thermophysics and Heat Transfer, Vol. 27, No. 3, July-September 2013, pp. 549-562; also AIAA Paper 2012-3304, June 2012.

${ }^{12}$ Gökçen, T., Alunni, A. I., Skokova, K. A., Chen, Y.-K., and Empey, D. M., "Analysis of Arc-Jet Tile Calibration Tests in the PTF: Compression-Pad Surface Heating Distribution,” AIAA Paper 2014-2816, June 2014. 